\title{
The role of biomarkers in evaluating human health concerns from fungal contaminants in food
}

\author{
Paul C. Turner ${ }^{1 *}$, Brenna Flannery ${ }^{2,3}$, Catherine Isitt $^{4}$, Mariyam Ali ${ }^{4}$ and James Pestka ${ }^{2,3,5}$ \\ ${ }^{1}$ Maryland Institute for Applied Environmental Health, School of Public Health, University of Maryland, \\ College Park, MD 20742, USA \\ ${ }^{2}$ Department of Food Science and Human Nutrition, Michigan State University, East Lansing, MI 48824, USA \\ ${ }^{3}$ Center for Integrative Toxicology, Michigan State University, East Lansing, MI 48824, USA \\ ${ }^{4}$ School of Medicine, University of Leeds, Leeds LS2 9JT, UK \\ ${ }^{5}$ Department of Microbiology and Molecular Genetics, Michigan State University, East Lansing, MI 48824-1224, USA
}

\begin{abstract}
Mycotoxins are toxic secondary metabolites that globally contaminate an estimated $25 \%$ of cereal crops and thus exposure is frequent in many populations. Aflatoxins, fumonisins and deoxynivalenol are amongst those mycotoxins of particular concern from a human health perspective. A number of risks to health are suggested including cancer, growth faltering, immune suppression and neural tube defects; though only the demonstrated role for aflatoxin in the aetiology of liver cancer is widely recognised. The heterogeneous distribution of mycotoxins in food restricts the usefulness of food sampling and intake estimates; instead biomarkers provide better tools for informing epidemiological investigations. Validated exposure biomarkers for aflatoxin (urinary aflatoxin $\mathrm{M}_{1}$, aflatoxin-N7-guaunine, serum aflatoxin-albumin) were established almost 20 years ago and were critical in confirming aflatoxins as potent liver carcinogens. Validation has included demonstration of assay robustness, intake $v$. biomarker level, and stability of stored samples. More recently, aflatoxin exposure biomarkers are revealing concerns of growth faltering and immune suppression; importantly, they are being used to assess the effectiveness of intervention strategies. For fumonisins and deoxynivalenol these steps of development and validation have significantly advanced in recent years. Such biomarkers should better inform epidemiological studies and thus improve our understanding of their potential risk to human health.
\end{abstract}

Key words: Aflatoxin: Deoxynivalenol: Fumonisin: Mycotoxin: Growth: Children: Cancer

\section{Background}

Fungi provide valuable contributions to the diet (mushrooms, cheeses), to medications (penicillins, statins), to food preservation (for example, citric acid production) and to fermentation, and even support complex chemical synthesis of novel compounds; however, some species frequently contaminate cereal crops, and under certain environmental conditions can produce potent toxins (mycotoxins) that can contaminate many dietary staples $^{(1,2)}$. These mycotoxins contaminate up to $25 \%$ of the world's cereal crops ${ }^{(1)}$. Whilst there are many hundreds of mycotoxins identified, only a few have received significant research activity. Those of major concern to human health include those toxins produced from Aspergillus and Penicillium, the aflatoxins and ochratoxins; and those produced from Fusarium, the fumonisins, trichothecenes (for example, deoxynivalenol (DON), nivalenol, T2-toxin) and zearalenone. Based on their current worldwide frequency of contamination, their established toxicity and our ability to understand exposure based on the use of existing and newly developed biomonitoring tools (also known as exposure biomarkers), the present review will focus on aflatoxins, fumonisins and DON. It is probable that the global distribution of mycotoxin contamination will change alongside anticipated climatic adjustments over the next century ${ }^{(3)}$, and that this change in distribution of mycotoxins may ultimately change the focus of this research area. The present review will highlight the known human health effects, the suspected health effects and the hypothesised mechanisms of toxicity, with a particular focus on children and growth, and their possible carcinogenic effects. The complex immune toxicologies of the mycotoxins are not reviewed.

Abbreviations: BW, body weight; COX-2, cyclo-oxygenase-2; DG, deoxynivalenol-glucuronide; DON, deoxynivalenol; FB, fumonisin B; fD, 'free' deoxynivalenol; HBV, hepatitis B virus; IGF, insulin-like growth factor; NTD, neural tube defect; SCCO, squamous-cell carcinomas of the oesophagus.

*Corresponding author: Dr Paul C. Turner, email pturner3@umd.edu 
Epidemiologists focused on understanding disparate disease aetiologies should remember that exposure to mycotoxins is almost unavoidable in cereal-consuming populations and, as a result, they have the capacity to negatively affect human health and modify human disease susceptibility.

Mycotoxins are typically resistant to processing and are stable in many cooking processes; thus complete avoidance without major dietary restriction is not feasible ${ }^{(1,2)}$. The specific type of mycotoxin produced is dependent in part on climatic conditions; aflatoxins and fumonisins are more prevalent in tropical and semi-tropical conditions whilst DON occurs in temperate climates ${ }^{(1,2)}$. The frequency and the amount of mycotoxin exposure are influenced by wealth ${ }^{(1-6)}$. In developed countries, wealth affords access to greater food choices and the freedom to avoid contaminated foods at the individual level and prevent it from entering commerce at the regulatory level. The poorest regions of the world have neither the infrastructure nor the luxury to allow for such decisions. Additionally, the wealthier countries can restrict imports of contaminated crops, resulting in an additional burden on developing countries ${ }^{(3,5,6)}$. Despite the differences in contamination levels, exposure to mycotoxins is apparent on all continents, but the impact on health in most instances remains poorly examined in all regions and requires significant research effort.

Whilst the consequences of individual mycotoxins are more typically examined, in reality typical exposures will include mixtures of mycotoxins, on a background of a wide range of other susceptibility factors that affect human health including additional chemical and biological agents, genetic susceptibility, varied nutrition and immune status. Thus, there is an increasing recognition of the need to examine multiple exposures to understand the health effects from mycotoxin exposures.

\section{Aspergillus and Fusarium mycotoxins}

Of the about 200 species of Aspergillus, $10 \%$ of these are harmful to man through a variety of mechanisms ${ }^{(1,2)}$. Aspergillus flavus and $A$. parasiticus produce a potent family of liver toxins, known as aflatoxins, whilst A. ochraceus produces the nephrotoxic ochratoxin A.

Aflatoxins predominately occur in hot and humid regions of the world where an estimated 4.5 billion individuals are at risk of exposure ${ }^{(5)}$. Aflatoxins contaminate dietary staples including maize and groundnuts; thus, populations highly reliant on these staples, and with limited agricultural capacity and storage facilities, are most frequently exposed though diet ${ }^{(5,6)}$. Biomarkerderived exposure data (see below) reveal that some of the world's poorest populations experience chronic exposure to aflatoxins throughout life, often at high levels.

Fusarium verticillioides (Sacc.) Nirenberg (formerly known as F. moniliforme Sheldon) and F. proliferatum
(Matsushima) Nirenberg are important fungi that contaminate maize and produce fumonisins ${ }^{(1,2,7)}$. Fumonisins predominantly contaminate maize in hot and humid climates, and co-contamination of maize with aflatoxins and fumonisins are reported $^{(8-18)}$. Chronic high levels of exposure are predicted in parts of South Africa, Central America and Asia. Fusarium graminearum (Gibberella zeae) and F. culmorum infection of wheat and maize in more temperate regions (Europe, North and South America and parts of Asia) causes significant economic loss in the form of head blight and contamination by DON and other related trichothecene mycotoxins $^{(1,2,19)}$. A survey of $>45000$ food items from countries within the European Union revealed that $57 \%$ of cereals tested were contaminated with DON, demonstrating the frequent contamination of this mycotoxin ${ }^{(20)}$.

\section{Biomarkers of exposure}

The presence of an accurately quantified amount of a toxin, and/or its metabolite(s), alone, is insufficient for a bio-measure to be classified as a biomarker. In the present review, an exposure biomarker is a biological measure which is correlated with the quantity of the xenobiotic ingested, resulting in improved exposure classification over approaches that are more traditional. The development and validation of aflatoxin exposure biomarkers occurred over 20 years ago ${ }^{(6,21,22)}$; they have been extensively reviewed elsewhere ${ }^{(6,21-23)}$ and so will not be discussed here in detail. The development of biomarkers for fumonisins and DON is more novel and the present review will highlight this.

\section{Aflatoxins}

The aflatoxins are a family of highly substituted coumarins containing a fused dihydrofurofuran moiety ${ }^{(23)}$. Aflatoxins $B_{1}, B_{2}, G_{1}$ and $G_{2}$ all occur naturally, whilst aflatoxin $B_{1}$ occurs most frequently and is the most toxic and carcinogenic (Fig. 1). In many developing countries, maize and groundnuts (peanuts) are the predominant contaminated food items, often at high levels. Aflatoxin metabolism (Fig. 2) gives rise to a variety of metabolites ${ }^{(23,24)}$ including aflatoxin $\mathrm{M}_{1}$, a frequent metabolite in milk of exposed lactating animals, including human breast milk following maternal exposure to dietary aflatoxin $\mathrm{B}_{1}{ }^{(23-25)}$. The parent toxins, aflatoxins $\mathrm{B}_{1}, \mathrm{G}_{1}$, etc., also occur in breast milk $^{(23,26,27)}$. The consequences of breast milk exposures to aflatoxins in the developing infant remain poorly examined.

Aflatoxin $B_{1}$ is metabolised by a number cytochrome $\mathrm{P} 450 \mathrm{~s}^{(28,29)}$ and generates two reactive epoxide species, an exo-8,9-epoxide and endo-8,9-epoxide, in addition to several hydroxy metabolites, for example, aflatoxins $M_{1}$, $\mathrm{Q}_{1}$ and $\mathrm{P}_{1}{ }^{(6,22,23)}$ (Fig. 2). The two epoxides are highly reactive and can cause cellular and macromolecule damage by covalently binding to proteins and nucleic 
(a)<smiles></smiles>

(c)<smiles>COc1cc2c(c3oc(=O)c4c(c13)CCC4=O)C1C2OC2O[B]C21</smiles>

(b)<smiles>COc1cc2c(c3oc(=O)c4c(c13)COC4=O)C1C=COC1OC2</smiles>

(d)<smiles>COc1cc2c(c3oc(=O)c4c(c13)COC4=O)C1C2OC2OC[B]C21</smiles>

Fig. 1. Structures of the four naturally occurring aflatoxins: (a) aflatoxin $B_{1}$; (b) aflatoxin $B_{2}$; (c) aflatoxin $G_{1}$; (d) aflatoxin $G_{2}$. The 8,9 position is where the reactive epoxide can be readily formed across the double bond. Me, methyl.

acids $^{(6,22,23,30)}$. The exo-epoxide is toxic and mutagenic; the specific role of the endo-epoxide is less well examined, but it is predicted to cause a similar level of toxicity as the exo-epoxide. The exo-epoxide additionally forms a stable covalent adduct with the N7 moiety of guanine ${ }^{(6,22,23,30)}$. Depurination at this site releases 8,9-dihydro-8-(N7guanyl)9-hydroxy aflatoxin $\mathrm{B}_{1}\left(\mathrm{AFB}_{1}-\mathrm{N} 7-\mathrm{Gua}\right)$, which is observed, in addition to aflatoxin $M_{1}$, in the urine of aflatoxin-dosed

animals and individuals exposed to aflatoxin through diet ${ }^{(31-36)}$. The urinary concentration of $\mathrm{AFB}_{1}-\mathrm{N} 7-\mathrm{Gua}$ in two separate studies $(r \quad 0.80, P<0.0001$; and $r 0.82$, $P<0.0001)$ and urinary aflatoxin $\mathrm{M}_{1}(r 0.82 ; P<0.0001)$ strongly correlated with aflatoxin intake in chronically exposed individuals, and both serve as validated exposure biomarkers ${ }^{(33-36)}$.

Hydrolysis of both epoxides to aflatoxin $\mathrm{B}_{1}-8$,9-dihydrodiol leads to a slow base-catalysed ring opening resulting in a resonating dialdehyde phenolate ion, capable of forming adducts with protein amino groups, particularly lysine ${ }^{(37,38)}$ (Fig. 2). One such protein adduct known as aflatoxin-albumin is present in the sera of aflatoxindosed animals and individuals naturally exposed to aflatoxin through diet ${ }^{(37-61)}$. The concentration of aflatoxin-albumin in sera was strongly correlated ( $r$ 0.69; $P<0.0001)$ with aflatoxin intake and provides an additional validated exposure biomarker ${ }^{(39,43)}$. The reliability of multiple measuring techniques (including immunoassay, HPLC and LC-MS) on a single set of samples by selected laboratories, and the long-term stability in cryopreserved samples provide additional confidence in its use as a valuable biomarker of exposure ${ }^{(62-64)}$. In high-risk regions of the world, greater than $95 \%$ of those individuals tested are positive for aflatoxin-albumin over a 3 log range, from

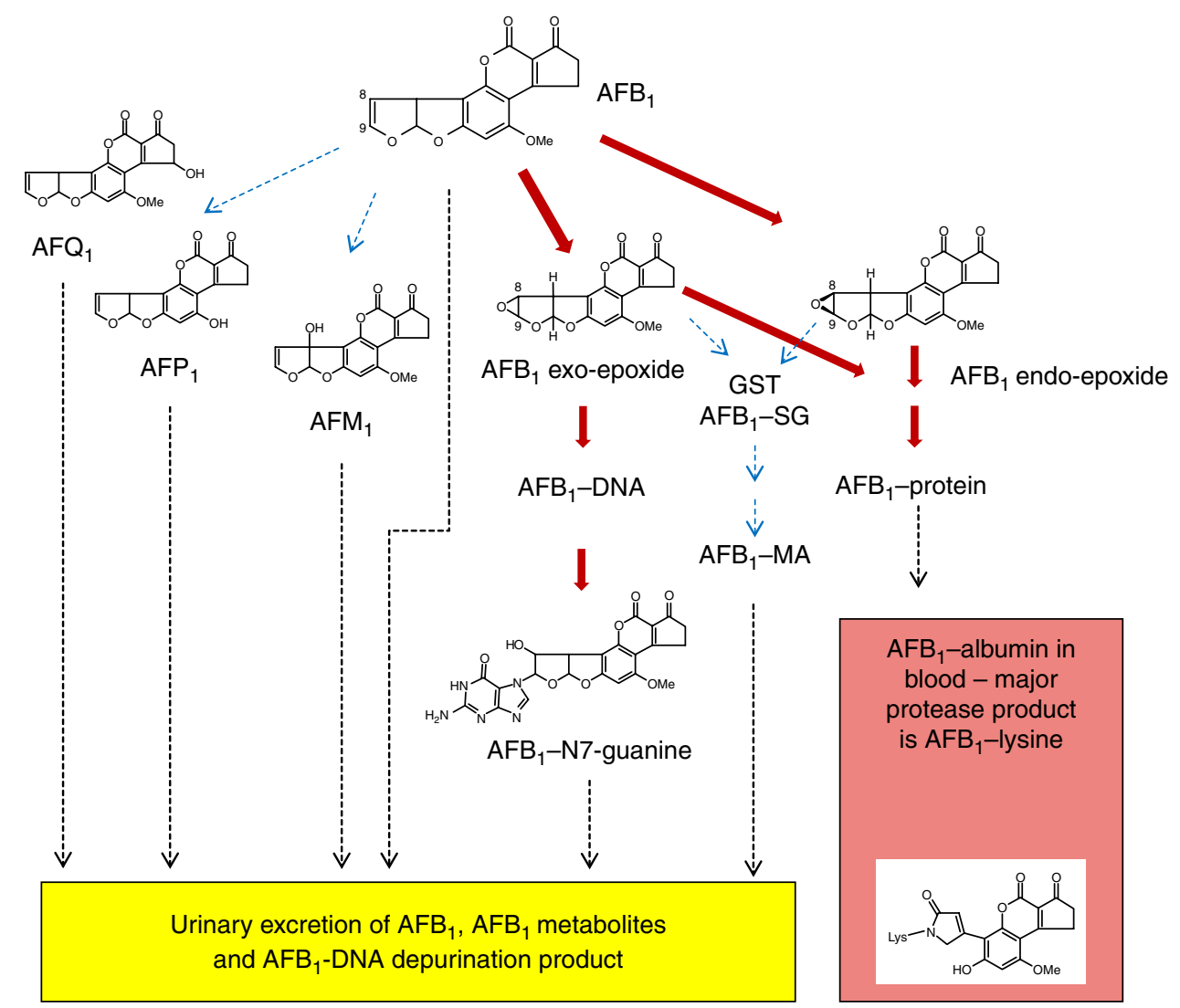

Fig. 2. Aflatoxin (AF) $B_{1}$ metabolism and biomarkers. Me, methyl; GST, glutathione $S$-transferase; SG, glutathione; MA, mercapturic acid; $\rightarrow$, epoxide-related toxicity pathways; $\cdots>$, non-epoxide-related toxicity pathways; $\cdots>$, excretion or blood routes. Adapted from Wild \& Turner ${ }^{(6)}$. (A colour version of this figure can be found online at www.journals.cambridge.org/nrr) 
approximately $3-5 \mathrm{pg} / \mathrm{mg}$ albumin to $>1000 \mathrm{pg} / \mathrm{mg}^{(37-59)}$, whilst more developed regions rarely have detectable levels of the biomarker ${ }^{(44,65)}$. Given that aflatoxins are genotoxic carcinogens, there is no safe threshold for exposure ${ }^{(5,6,21-23)}$. Whilst unmetabolised aflatoxin $\mathrm{B}_{1}$ occurs in the urine of exposed individuals, there is no significant correlation with intake ${ }^{(33)}$, perhaps in part due to extensive metabolism of the parent toxin to various metabolites. Thus, urinary aflatoxin $\mathrm{B}_{1}$ itself is not a useful indicator of the amount of aflatoxin exposure ${ }^{(6,22,33-36,39)}$.

\section{Fumonisins}

Fumonsins are secondary metabolites produced by $F$. verticillioides (Sacc.) Nirenberg and $F$. proliferatum (Matsushima) Nirenberg, primarily in maize grown in hot and humid climates ${ }^{(1,2,23)}$. Whilst numerous fumonisin analogues are described, the fumonisin B (FB) series predominates, and within this series the occurrence frequency is $\mathrm{FB}_{1}>\mathrm{FB}_{2}>\mathrm{FB}_{3} ; \mathrm{FB}_{1}$ (Fig. 3) is reported to represent on average about $70 \%$ of the fumonisins in naturally contaminated maize ${ }^{(66)}$. Fumonisins do not appear to undergo significant metabolism ${ }^{(67-73)}$; thus biomarker development has not followed the metabolite profile approach used for aflatoxins.

Fumonisins mimic naturally occurring sphingoid bases, and inhibit sphingolipid metabolism via competing with ceramide synthase ${ }^{(67,74,75)}$. Fumonisin modulation of sphingoid base (sphinganine and sphingosine) concentrations in dosed animals has been reviewed ${ }^{(74-77)}$, and this disruption is plausibly linked to their mechanism of toxicity ${ }^{(67,76-78)}$ including liver and kidney cancer, and neural tube defects (NTD). The capacity of fumonisins to alter levels of sphingoid bases, as observed in experimental animals, highlighted the possibility that their measurement in human bio-fluids may yield a useful exposure biomarker, though to date no such biomarker has been established. Due to the limited metabolism of fumonisin, measurement of the concentration of the parent compound in bio-fluids provides an alternative route for developing a biomarker. Animal studies indicate that the transfer of fumonisins to urine was about $0 \cdot 4-2 \cdot 0 \%$ of that ingested $^{(68-73)}$, though typically these percentages refer to total transfer over several days, and often at doses higher than would be observed in human subjects.

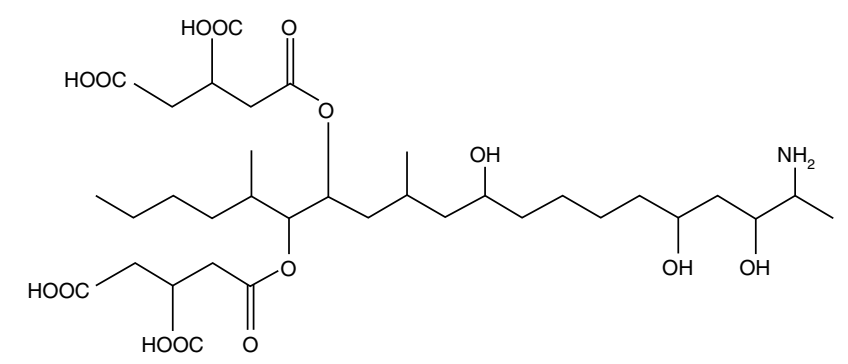

Fig. 3. Structure of fumonisin $B_{1}$.
There have been relatively few studies in human subjects reporting urinary $\mathrm{FB}_{1}$ measurements. In one study, a subset of Mexican (Morelos County) women were selected based on tortilla consumption (lowest ( $n$ 25), medium ( $n$ 25) and highest ( $n$ 25)) from a larger cohort ( $n$ 996), and their urine analysed for $\mathrm{FB}_{1}{ }^{(79)}$. Overall, fifty-six of seventy-five women $(74.6 \%)$ had detectable urinary $\mathrm{FB}_{1}(>20 \mathrm{pg} / \mathrm{ml})$ (range of non-detectable to $9312 \mathrm{pg} / \mathrm{ml}$ ). Urinary $\mathrm{FB}_{1}$ was detected more frequently in the high (96\%) compared with the medium (80\%) and the low (45\%) consumption groups, and the geometric means were associated $(P<0.001)$ with consumption of tortillas (geometric means and 95th percentiles were 147 (88, 248), 63 (37, $108)$ and $35(19,65) \mathrm{pg} / \mathrm{ml}$, respectively). No food samples were collected from this survey; though based on the urinary measures, Gong et al. ${ }^{(79)}$ cautiously estimated $\mathrm{FB}_{1}$ intake in this region to range from non-detectable to $23 \mu \mathrm{g} / \mathrm{kg}$ body weight (BW) per $\mathrm{d}$, using a number of assumptions, including estimated average transfer from animal models. The provisional maximum tolerable daily intake for $\mathrm{FB}_{1}, \mathrm{FB}_{2}$ and $\mathrm{FB}_{3}$ combined or individually is $2 \mu \mathrm{g} / \mathrm{kg}$ BW per $\mathrm{d}^{(80)}$ and, consequently, fumonisin exposure is a significant health concern in this region.

Urinary $\mathrm{FB}_{1}$ was also measured in the urine from Chinese adults from Huaian County, Jiangsu Province ( $n$ 43) and Fusui County, Guangxi Zhuang Autonomous Region ( $n$ 34). The frequency of urinary $\mathrm{FB}_{1}$ detection was similar in both regions, with 84 and $83 \%$ of samples positive for $\mathrm{FB}_{1}$, respectively, though the mean concentrations were significantly higher in Huaian county $(13630 \mathrm{pg} / \mathrm{mg}$ creatinine: range non-detectable to $256000 \mathrm{pg} / \mathrm{mg}$; median $3910 \mathrm{pg} / \mathrm{mg}$ ) as compared with Fusui county $(720 \mathrm{pg} / \mathrm{mg}$ : range non-detectable to $3720 \mathrm{pg} / \mathrm{mg}$; median $390 \mathrm{pg} / \mathrm{mg}$ ). Moreover, the average estimated FB intakes were about three- to four-fold higher in the Huaian region ${ }^{(81)}$. These data would suggest that about $1-2 \%$ of the ingested FB was transferred to urine. However, FFQ information and food measures of household items for $\mathrm{FB}_{1}$ were used to estimate typical $\mathrm{FB}_{1}$ intake. No significant correlation between urinary $\mathrm{FB}_{1}$ and estimated intake was found, an observation likely to reflect that the FFQ used measured typical intakes over weeks rather than recent intake (in d) at the time of urine collection. Regardless, in both regions, the mean predicted intake of fumonisin was similar to that in Mexico ${ }^{(79)}$ and South Africa $^{(82)}$, and the provisional maximum tolerable daily intake will frequently be exceeded.

A more targeted validation approach to assess the relationship between urinary $\mathrm{FB}_{1}$ and $\mathrm{FB}_{1}$ ingestion was attempted in South Africa ${ }^{(82)}$. Here, urinary $\mathrm{FB}_{1}$ was measured on two consecutive days whilst $\mathrm{FB}_{1}$ intake was assessed using plate-ready food (a maize porridge) on the days immediately before urine collection. Here, the resulting urinary $\mathrm{FB}_{1}$ concentrations were roughly of the same order as those in both Mexico $^{(79)}$ and Fusui County, China ${ }^{(81)}$, but significantly lower than those reported in Huaian County, China ${ }^{(81)}$. In the South African 
study the geometric mean daily estimated $\mathrm{FB}_{1}$ consumption over $2 \mathrm{~d}$ was $4 \cdot 84$ (95th percentiles $2 \cdot 87,8 \cdot 14) \mu \mathrm{g} / \mathrm{kg}$ $\mathrm{BW}$ per $\mathrm{d}$, and the geometric mean urinary $\mathrm{FB}_{1}$ concentration for subsequent mornings' first void was $225\left(95 \%\right.$ CI 144, 350) pg/ml. Urinary $\mathrm{FB}_{1}$ data were also presented after adjustment for creatinine (geometric mean $470(95 \%$ CI 295,750$) \mathrm{pg} / \mathrm{mg})$. After data were natural log-transformed, a statistically significant, albeit moderate correlation $\left(r^{2} 0.31\right)$ was observed between estimated $\mathrm{FB}_{1}$ intake/kg BW per $\mathrm{d}$ and urinary $\mathrm{FB}_{1}$ adjusted for creatinine. Based on rough estimates (by authors of the present review) back-transformed data suggest that the highest estimated intake of $\mathrm{FB}_{1}$ was $90 \mu \mathrm{g} / \mathrm{kg} \mathrm{BW}$ per $\mathrm{d}$ (forty-five times the recommended tolerable daily intake for $\mathrm{FB}_{1}$ ) and the highest urinary $\mathrm{FB}$ concentration was approximately $4900 \mathrm{pg} / \mathrm{mg}$; these were not measures for the same individual. The reported correlation used natural log-transformed data, and whilst statistically appropriate, comparisons of the correlations or $r^{2}$ values in this survey and those used in part to validate other mycotoxin exposure markers are not straightforward. The authors of the South Africa study additionally conducted a successful hand-sorting and kernel-washing intervention on the maize to reduce $\mathrm{FB}$ contamination in $\mathrm{it}^{(82)}$. Overall, a significant $(P<0.05) 62 \%$ reduction in estimated $\mathrm{FB}_{1}$ intake was reported based on $\mathrm{FB}_{1}$ in plate-ready maize porridge before and following the intervention, whilst a borderline $(P=0.06) 41 \%$ reduction in mean urinary $\mathrm{FB}_{1}(\mathrm{pg} \mathrm{FB} 1 / \mathrm{mg}$ creatinine) was reported. Further, this paper presented an estimate of the transfer of $\mathrm{FB}_{1}$ to urine to be approximately $0.075 \%$ of that ingested, a value comparable with, but slightly lower than that reported in animals ${ }^{(68-73)}$ and similar to values in a limited human kinetics study conducted in the USA ${ }^{(83)}$. Based on this quantitative data, urinary $\mathrm{FB}_{1}$ was regarded as an exposure biomarker for fumonisin ${ }^{(82)}$.

Urinary $\mathrm{FB}_{1}$ concentrations were more moderate in a recent report from Sri Lanka, though biomarker validation was not discussed ${ }^{(84)}$. Further confirmatory work in using urinary fumonisin as an exposure biomarker in humans is anticipated, including stability studies, with additional interest in measurements of modified sphingoid bases, rather than the unsuccessful alternative putative markers of fumonisin exposure (at least to date) that utilised sphinganine and sphingosine bio-measures ${ }^{(76,85)}$.

\section{Deoxynivalenol}

DON is a type B trichothecene mycotoxin (Fig. 4) which is predominantly associated with crop contamination with Fusarium graminearum (Gibberella zeae) and $F$. culmorum fungi. Both of these fungi are important plant pathogens that cause Fusarium head blight in wheat and Gibberella ear rot in maize ${ }^{(1)}$. Also known as vomitoxin, DON is a common contaminant of cereals such as wheat, maize and barley ${ }^{(19,86)}$. The potent gastrointestinal effects (and hence 'vomitoxin') in animals and

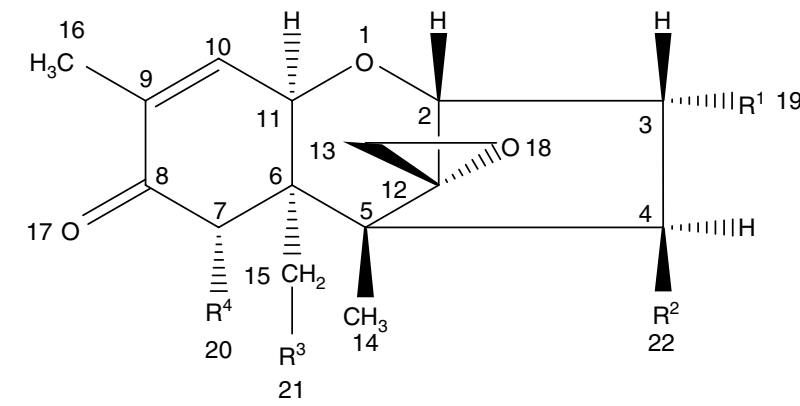

\begin{tabular}{|l|c|c|c|c|}
\hline & $\mathrm{R}^{1}$ & $\mathrm{R}^{2}$ & $\mathrm{R}^{3}$ & $\mathrm{R}^{4}$ \\
\hline Nivalenol & $\mathrm{OH}$ & $\mathrm{OH}$ & $\mathrm{OH}$ & $\mathrm{OH}$ \\
\hline Deoxynivalenol & $\mathrm{OH}$ & $\mathrm{H}$ & $\mathrm{OH}$ & $\mathrm{OH}$ \\
\hline 3-Acetyl-deoxynivalenol & $\mathrm{OCOCH}_{3}$ & $\mathrm{H}$ & $\mathrm{OH}$ & $\mathrm{OH}$ \\
\hline 15-Acetyl-deoxynivalenol & $\mathrm{OH}$ & $\mathrm{H}$ & $\mathrm{OCOCH}_{3}$ & $\mathrm{OH}$ \\
\hline Fusarenon X & $\mathrm{HO}$ & $\mathrm{OCOCH}_{3}$ & $\mathrm{OH}$ & $\mathrm{OH}$ \\
\hline
\end{tabular}

Fig. 4. Generic structure of type $B$ trichothecenes, including deoxynivalenol.

suspected in humans have been reviewed in detail ${ }^{(19,86)}$ and not discussed further.

In resistant animal species, DON is readily detoxified by gut microbiota to a de-epoxy metabolite known as DOM-1 (de-epoxydeoxynivalerol) ${ }^{(87-90)}$, though this pathway was not apparent in a small survey of human faecal metabolism $^{(91)}$. DON can also be metabolised in the liver to a glucuronide ${ }^{(19,86)}$. Based on DON metabolism and toxicokinetics in the rat and a pilot survey in human subjects, the combined measure of unmetabolised DON or 'free' DON (fD) and DON-glucuronide (DG), subsequently referred to here as urinary $\mathrm{fD}+\mathrm{DG}$, was suggested as a putative urinary exposure biomarker by Meky et al. ${ }^{(92)}$. Improved DG enzymic digestion conditions to release fD, and the use of $\left[{ }^{13} \mathrm{C}_{15}\right] \mathrm{DON}$ as an internal standard have provided significant improvements in precision and accuracy in the urinary assay ${ }^{(93)}$. The process of validating this putative exposure biomarker was subsequently undertaken using this modified assay.

In a survey of UK adults, urinary DON was measured in a subset of 300 individuals selected based on cereal consumption from the $2 \mathrm{nd} / 3 \mathrm{rd}$, the $5 \mathrm{th} / 6$ th and the 9 th deciles (100 individuals from each group) from a larger cohort of 1724 individuals. Urinary fD + DG was detected in $98.7 \%$ of individuals (geometric mean 8.9 (95\% CI 8.2, 9.7; range non-detectable-48.2) $\mathrm{ng} / \mathrm{mg})^{(94)}$. A modest, but significant, positive association was observed between the urinary measure and cereal consumption $(P<0 \cdot 001$; $r^{2}$ 0.23). Of the cereal items consumed, bread predominated in both frequency and mean level of consumption. In order to improve our understanding of the role of cereal in the diet and its relation to the biomarker concentration, a wheat restriction intervention was used to assess the effects of a $4 \mathrm{~d}$ avoidance of major sources of dietary DON on subsequent urinary fD + DG concentration. The intervention reduced wheat intake by $>90 \%$, and the urinary concentration of $\mathrm{fD}+\mathrm{DG}$ was also significantly 
$(P<0.001)$ reduced (geometric mean pre-intervention $7 \cdot 2(95 \%$ CI $4.9,10.5) \mathrm{ng} / \mathrm{mg}$ ) by $>90 \%$ (geometric mean post-intervention $0.6(95 \% \mathrm{CI} 0 \cdot 4,0 \cdot 9) \mathrm{ng} / \mathrm{mg})^{(88)}$. This intervention restricted the types of food consumed rather than attempting to reduce the contamination level within the consumed food; thus readers should avoid a direct comparison of this outcome with that of the FB intervention above ${ }^{(82)}$. The intervention on DON was a more simple study to improve our understanding of the biomarker, whilst the FB intervention was a more practical study aimed at providing a solution to the exposure. These data on DON provided further support for the approach of Meky et al. ${ }^{(92)}$ using urinary fD + DG as an exposure biomarker.

Subsequently the concentration of urinary $\mathrm{fD}+\mathrm{DG}$ was assessed over a longer period ( $6 \mathrm{~d}$ ) during the consumption of the normal diet ${ }^{(95)}$. The frequency of detection and range were similar to those of earlier studies (geometric mean $10.1 \mathrm{ng} / \mathrm{mg}$ creatinine; range non-detectable $-70.7 \mathrm{ng} / \mathrm{mg}$ ); again, the concentration of DON was significantly, but moderately, associated with cereal intake $\left(R^{2} 0.23 ; P<0 \cdot 001\right)$. A 4 d dietary restriction was then initiated in which bread provided the only major source of cereals potentially contaminated with DON; consumption of alternative starch-based foods were suggested to maintain energy intake (for example, rice, potatoes). Participants provided a duplicate portion of every bread sample consumed for DON analysis, and they recorded the quantity consumed of each bread sample. The mean bread consumption was 155 (range $0-455$ ) $\mathrm{g} / \mathrm{d}$. The mean contamination level of the bread was 74 (range 20-316) $\mu \mathrm{g} / \mathrm{kg}$, and the estimated average daily intake of DON was 10.6 (range $0-42.5) \mu \mathrm{g} / \mathrm{d}$. On a daily basis, urinary $\mathrm{fD}+\mathrm{DG}$ was correlated with DON intake $\left(P<0.001 ; r^{2} 0.56,0.49,0.54,0.64\right.$, for each day respectively), and a more integrated assessment of the $4 \mathrm{~d}$ combined revealed a highly significant correlation $\left(r^{2} 0.74\right.$; $P<0 \cdot 001)$. After adjustment for age, sex and BMI, all correlations remained significant $\left(P<0 \cdot 001\right.$; adjusted $r^{2} 0.63$, $0.68 .0 .65,0.63$ and 0.83 , respectively), providing the first data of a strong quantitative relationship between exposure and the urinary biomarker.

Further studies have been initiated to assess the stability of urinary $\mathrm{fD}+\mathrm{DG}$ during the collection phase when samples may be at ambient temperature for prolonged periods (hours), and during the cryopreservation period (years). No losses were observed in samples stored at ambient temperature $\left(18^{\circ} \mathrm{C}\right)$ for up to $24 \mathrm{~h}$, or at $4^{\circ} \mathrm{C}$ for $48 \mathrm{~h}$. No reduction in biomarker levels were found in cryopreserved samples kept at $-40^{\circ} \mathrm{C}$ for up to 3 years ${ }^{(96)}$. In studies to date DG appears to be the major metabolite of DON in human urine, whilst the de-epoxy metabolite has rarely been observed ${ }^{(92-101)}$. Urinary fD + DG represents best exposure in the previous $24-48 \mathrm{~h}^{(95,102)}$, though average cereal intake over $7 \mathrm{~d}$ was significantly, but not as strongly, associated with the biomarker. Additionally, 
colleagues in Austria are investigating a putative direct measure of urinary $\mathrm{DG}^{(103)}$. The combined measure of urinary $\mathrm{fD}+\mathrm{DG}$ now serves as a validated exposure biomarker for DON intake ${ }^{(93-95,99,100)}$, at least in moderately exposed populations. To date, populations predicted to have the highest DON exposures remain unexamined with this assay ${ }^{(93)}$. Nevertheless, for all of the European studies to date, approximately $1-5 \%$ of the population of adults are predicted to exceed the recommended tolerable daily intake of $1 \mu \mathrm{g} / \mathrm{kg} \mathrm{BW}$ per $\mathrm{d}^{(104)}$. An earlier and perhaps less robust version of this assay was used to analyse urinary $\mathrm{fD}+\mathrm{DG}$ in a pilot survey in a high-risk region of China $^{(92)}$. Data from that survey revealed a mean level of urinary $\mathrm{fD}+\mathrm{DG}$ about three to four times greater than the mean reported in surveys of Europeans ${ }^{(100)}$. Urinary $\mathrm{fD}+\mathrm{DG}$ has now been observed in studies from the UK, France, Sweden and China ${ }^{(100)}$, and independently in Spain and Italy ${ }^{(105,106)}$, whilst urinary DG was observed in Austrians ${ }^{(103)}$.

All of the mycotoxin biomarker approaches discussed here are summarised in Table 1; ochratoxin $\mathrm{A}$ is additionally included for completeness, as the only other mycotoxin for which biomarker development has been reported $^{(107)}$. Summaries of aflatoxin biomarker surveys are in numerous reviews; here only aflatoxin-albumin biomarkers are presented from studies of West African infants and children (Table 2), as these relate to latter sections of this review. A summary of surveys on Fusarium biomarkers is included (Tables 3 and 4).

It is also prudent to emphasise a significant difference in the urinary assays for aflatoxin, fumonisin and DON. Whilst the analytical sensitivity may be suggestive of greater, lesser or a similar sensitivity in the exposure assessment, the overall sensitivity of the bio-measurement is also related to the transfer kinetics of the toxins. If, for example, we compare urinary biomarkers for aflatoxin $\mathrm{M}_{1}, \mathrm{FB}_{1}$ and $\mathrm{fD}+\mathrm{DG}$, the analytical limits of detection are 5, 20 and $500 \mathrm{pg} / \mathrm{ml}$, respectively, whilst the mean estimated amounts transferred to urine are about 2, 0.075 and $72 \%$, respectively. Assuming average BW of about $65 \mathrm{~kg}$ and 1.5 litres of urine excreted, the limits of detection correspond to a mean intake of $0.006,0.615$ and $0.015 \mu \mathrm{g} / \mathrm{kg}$ BW per $\mathrm{d}$, respectively. Thus, similar levels of these biomeasures in urine do not represent similar levels of exposure, and across a range of typical human exposures, urinary DON will be detected more frequently than $\mathrm{FB}_{1}$, for example, despite a greater analytical sensitivity for $\mathrm{FB}_{1}$ compared with DON.

\section{Mycotoxins and human disease}

In many parts of the developing world, chronic exposure to aflatoxins at high levels remains a significant health burden ${ }^{(5-7,21-23,108-110)}$. About 20 years ago, aflatoxin $\mathrm{B}_{1}$ was classified as a potent liver carcinogen ${ }^{(23)}$, a conclusion in part defined using the above biomarkers, and mentioned only briefly here; readers are directed to an excellent recent review of the topic ${ }^{(22)}$ for further details. This section of the review will focus more on the recent observation between aflatoxin and growth faltering.

\section{Aflatoxins and liver cancer}

In high-risk parts of Asia and Africa $>95 \%$ of populations studied to date are chronically exposed to aflatoxins ${ }^{(5,6,21-23)}$. Aflatoxins are potent liver toxins and it is likely that a combination of non-specific liver damage/ toxicity and specific DNA damage via aflatoxin exo-epoxide covalently binding to N7-guanine of DNA contribute to the carcinogenicity of aflatoxins $^{(5-7,21-23)}$. It is notable that a synergistic interaction between aflatoxin and hepatitis $\mathrm{B}$ virus (HBV) occurs ${ }^{(22,23)}$, perhaps in part a reflection of modulation of aflatoxin metabolism (favouring activation over detoxification) and liver regeneration in HBV-infected individuals ${ }^{(55)}$; this effect may enrich the liver for mutations caused by aflatoxin-DNA damage. One important facet of

Table 2. Summary of some aflatoxin-albumin survey data in West African children*

\begin{tabular}{|c|c|c|c|c|c|c|}
\hline \multirow[b]{2}{*}{ Country } & \multirow[b]{2}{*}{ Subjects $(n)$} & \multicolumn{2}{|c|}{$\begin{array}{l}\text { Aflatoxin-albumin } \\
\qquad(\mathrm{pg} / \mathrm{mg})\end{array}$} & \multirow[b]{2}{*}{$\%$ Positive } & \multirow[b]{2}{*}{ Age group } & \multirow[b]{2}{*}{ Reference } \\
\hline & & Mean & Range & & & \\
\hline Benin and Togo & 479 & 33 & nd-1064 & 99 & Child & Gong et al. ${ }^{(48)}$ \\
\hline \multirow{3}{*}{ Benint } & 200 & 37 & $n d-688$ & 98 & Child & Gong et al. ${ }^{(49)}$ \\
\hline & 200 & 39 & nd-744 & 99 & Child & \\
\hline & 200 & 88 & $5-1568$ & 100 & Child & \\
\hline Guinea & 124 & 9 & nd-262 & 96 & Child & Turner et al. ${ }^{(51)}$ \\
\hline \multirow{3}{*}{ The Gambia } & 119 & 40 & $5-261$ & 100 & Pregnant & Turner et al. ${ }^{(52)}$ \\
\hline & 99 & 10 & $5-190$ & 49 & Cord & \\
\hline & 118 & 9 & $5-30$ & 11 & 16 weeks & \\
\hline The Gambia & 128 & 60 & nd-391 & 92 & 52 weeks & Turner et al. ${ }^{(53)}$ \\
\hline The Gambia & 466 & 24 & $\mathrm{nd}-456$ & 93 & Child & Turner et al. ${ }^{(54)}$ \\
\hline The Gambia & 444 & 41 & $3-459$ & 100 & Child & Turner et al. ${ }^{(55)}$ \\
\hline The Gambia & 391 & 57 & nd -720 & 83 & Child & Allen et al. ${ }^{(46)}$ \\
\hline
\end{tabular}

nd, Non-detectable.

*Adapted from Turner et al. ${ }^{(53)}$

† A total of 200 children measured at three time points within an 8-month period. 
Table 3. Exposure biomarker surveys for the Fusarium mycotoxin fumonisin $\mathrm{B}_{1}$ *

(Mean values and $95 \%$ confidence intervals)

\begin{tabular}{|c|c|c|c|c|c|c|c|c|}
\hline & \multirow[b]{2}{*}{$n$} & \multicolumn{2}{|c|}{$\begin{array}{l}\text { Detection } \\
\text { rate }\end{array}$} & \multicolumn{2}{|c|}{$\begin{array}{l}\text { Fumonisin } \\
\mathrm{B}_{1}(\mathrm{pg} / \mathrm{ml})\end{array}$} & \multicolumn{2}{|c|}{$\begin{array}{c}\text { Fumonisin } \\
\mathrm{B}_{1} \text { (pg/mg creatinine) }\end{array}$} & \multirow[b]{2}{*}{ Reference } \\
\hline & & $n$ & $\%$ & Mean & $95 \% \mathrm{Cl}$ & Mean & $95 \% \mathrm{Cl}$ & \\
\hline Mexico† (low consumption group) & 25 & $11 / 25$ & 44 & 35 & 19,65 & 44 & 22,87 & Gong et al. ${ }^{(79)}$ \\
\hline Mexico† (medium consumption group) & 25 & $20 / 25$ & 80 & 63 & 37,108 & 92 & 37,108 & Gong et al. ${ }^{(79)}$ \\
\hline Mexico† (high consumption group) & 25 & $24 / 25$ & 96 & 147 & 88,248 & 134 & 79,228 & Gong et al. ${ }^{(79)}$ \\
\hline Centane, South Africa (baseline) & 22 & $43 / 44 \ddagger$ & 98 & 225 & 144,350 & 470 & 295,750 & van der Westhuizen et al. ${ }^{(82)}$ \\
\hline Centane, South Africa (intervention) & 21 & $40 / 42 \ddagger$ & 95 & 109 & 85,138 & 279 & 202,386 & van der Westhuizen et al. ${ }^{(82)}$ \\
\hline Huaian, China & 43 & $36 / 43$ & 84 & - & - & 13630 & Range $60-253000$ & Xu et al. ${ }^{(81)}$ \\
\hline Fusui, China & 34 & $28 / 34$ & 82 & - & - & 720 & Range $10-3720$ & Xu et al. ${ }^{(81)}$ \\
\hline
\end{tabular}

* Geometric means are reported except for the study in China ${ }^{(116)}$.

† Overall, $56 / 75$ were positive $(>20 \mathrm{pg} / \mathrm{ml}):$ mean $70 \mathrm{pg} / \mathrm{ml}$; range non-detectable to $9312 \mathrm{pg} / \mathrm{ml}$.

¥Urinary data are the mean of $2 \mathrm{~d}$ data, overall range of data non-detectable to $3900 \mathrm{pg} / \mathrm{ml}$ (estimated by the authors of the present review).

this is an apparent difference in susceptibility of children compared with adults. In The Gambia, chronic exposure to aflatoxins is ubiquitous ${ }^{(25,42,44-46)}$; although Gambian adults chronically carrying HBV and those without HBV have a similar aflatoxin-albumin biomarker level ${ }^{(46)}$, a significantly higher mean and range of aflatoxin-albumin adduct levels were apparent in young Gambian children with HBV compared with non-carriers ${ }^{(55)}$. Aflatoxinalbumin and aflatoxin-DNA damage are correlated; thus, while the temporal nature of this observation awaits further research, if HBV does increase body burden of the activated toxin (the epoxide) then it is occurring at a time of rapid cell growth and provides an opportunity to enrich any resultant mutations. Additionally, the damage is occurring early in life and thus affords an extensive timeframe for any effects to manifest.
The global burden of liver cancer is about 550000 to 600000 cases annually, predominantly due to hepatitis infections and aflatoxins ${ }^{(23)}$. It was estimated that up to $28 \%$ of this burden might be due to aflatoxin alone ${ }^{(108)}$ Moreover, the onset of liver cancer in populations with both HBV and aflatoxin is significantly earlier than those with just $\mathrm{HBV}^{(5-7,21-23,108109)}$, such that reductions in aflatoxin exposure may reduce not only the occurrence, but delay the onset of disease ${ }^{(22)}$. To improve our understanding of this potential mechanism, it would be of value to assess more detailed aflatoxin metabolite profiles in both HBV carriers and non-carriers. Such information may support intervention strategies that combine both reductions in exposure ${ }^{(111)}$ and dietary modulation of aflatoxin metabolism (for reviews, see $\operatorname{Kensler}^{(22)}$ and Wogan et al. $\left.{ }^{(109)}\right)$.

Table 4. Exposure biomarker surveys for the Fusarium mycotoxin deoxynivalenol

\begin{tabular}{|c|c|c|c|c|c|c|c|c|c|}
\hline & \multirow[b]{2}{*}{$n$} & \multicolumn{2}{|c|}{$\begin{array}{l}\text { Detection } \\
\text { rate }\end{array}$} & \multicolumn{2}{|c|}{$\begin{array}{l}\text { Deoxynivalenol } \\
\text { (ng/ml) }\end{array}$} & \multicolumn{3}{|c|}{$\begin{array}{c}\text { Deoxynivalenol } \\
\text { (ng/mg creatinine) }\end{array}$} & \multirow[b]{2}{*}{ Reference } \\
\hline & & $n$ & $\%$ & Mean & Range & Mean & Range & $95 \% \mathrm{Cl}$ & \\
\hline China (high risk) & 9 & 9/9 & 100 & 37 & $14-94$ & - & - & - & Meky et al. (92) \\
\hline China (moderate risk) & 6 & $6 / 6$ & 100 & 12 & $4-18$ & _- & _ & _- & Meky et al. ${ }^{(92)}$ \\
\hline $\mathrm{UK}^{\star}$ (normal diet) & 25 & $25 / 25$ & 100 & 11 & $1-61$ & 7 & - & 5,11 & Turner et al. ${ }^{(93)}$ \\
\hline UK* (intervention diet) & 25 & $17 / 25$ & 68 & 1 & nd-8 & $<1$ & _- & $<1$ & Turner et al. ${ }^{(93)}$ \\
\hline $\mathrm{UK}^{*}$ (2nd/3rd percentile group) & 100 & $97 / 100$ & 97 & 5 & $\mathrm{nd}-20$ & 7 & - & 6,8 & Turner et al. ${ }^{(94)}$ \\
\hline UK$^{\star}$ (5th/6th percentile group) & 100 & $99 / 100$ & 99 & 8 & $n d-56$ & 9 & - & 8,11 & Turner et al. ${ }^{(94)}$ \\
\hline UK$^{*}$ (9th percentile group) & 100 & $100 / 100$ & 100 & 9 & nd-45 & 11 & - & 9,12 & Turner et al. ${ }^{(94)}$ \\
\hline \multicolumn{10}{|l|}{ UK normal diet } \\
\hline Day 1 & 35 & $35 / 35$ & 100 & - & - & 9 & $1-49$ & - & Turner et al. ${ }^{(95)}$ \\
\hline Day 2 & 35 & $34 / 35$ & 97 & - & - & 8 & nd-59 & - & Turner et al. ${ }^{(95)}$ \\
\hline Day 3 & 35 & $31 / 35$ & 86 & - & - & 9 & nd-78 & - & Turner et al. ${ }^{(95)}$ \\
\hline Day 4 & 35 & $34 / 35$ & 97 & _- & _- & 12 & nd-49 & _- & Turner et al. ${ }^{(95)}$ \\
\hline Day 5 & 35 & $32 / 35$ & 91 & - & - & 10 & $\mathrm{nd}-58$ & - & Turner et al. ${ }^{(95)}$ \\
\hline Day 6 & 35 & $33 / 35$ & 94 & - & - & 9 & nd-62 & - & Turner et al. ${ }^{(95)}$ \\
\hline \multicolumn{10}{|l|}{ UK intervention diet } \\
\hline Day 1 & 10 & $6 / 10$ & 60 & _- & _- & $<1$ & $n d-3$ & _- & Turner et al. ${ }^{(95)}$ \\
\hline Day 2 & 10 & $5 / 10$ & 50 & - & - & $<1$ & nd-3 & - & Turner et al. ${ }^{(95)}$ \\
\hline Day 3 & 10 & $3 / 10$ & 30 & - & - & $<1$ & $\mathrm{nd}-2$ & - & Turner et al. ${ }^{(95)}$ \\
\hline Day 4 & 10 & $2 / 9$ & 22 & - & - & $<1$ & nd-1 & - & Turner et al. ${ }^{(95)}$ \\
\hline UK (pregnancy) & 86 & $85 / 86$ & $\begin{array}{l}22 \\
99\end{array}$ & - & - & 10 & $\mathrm{nd}-117$ & - & Hepworth et al. ${ }^{(97)}$ \\
\hline French male farmers & 76 & $75 / 76$ & 99 & _- & _- & 7 & nd-29 & _- & Turner et al. ${ }^{(96)}$ \\
\hline Swedish & 29 & $28 / 29$ & 97 & - & - & 11 & nd -66 & - & Turner et al. ${ }^{(100)}$ \\
\hline
\end{tabular}

nd, Non-detectable.

* Both interventions were voluntary restrictions of major sources of dietary wheat products. The two studies have completely independent data. 


\section{Aflatoxins and growth faltering}

In animals, aflatoxins suppress the immune system and cause growth faltering ${ }^{(112,113)}$. Given the frequent chronic human exposure to this toxin, it is important to understand whether typical levels of ingestion in some high-risk regions restrict growth in children.

\section{Aflatoxin-albumin exposure patterns in infants}

Longitudinal biomarker data on aflatoxin exposure during the peri-natal and postnatal period are limited in the literature. One longitudinal study in The Gambia revealed a pattern of maternal, cord blood, week-16 infant and week-52 infant aflatoxin-albumin adducts at 100\% (range 5-400 pg/mg), 49\% (range non-detectable-50 pg/mg), $11 \%$ (non-detectable-50 pg/mg) and $92 \%$ (non-detectable$390 \mathrm{pg} / \mathrm{mg}$ ) positive, respectively ${ }^{(52,53)}$. Whilst no data are available on infants from developed countries, a recent survey in North American adults revealed that less than $1 \%$ would exceed $3-5 \mathrm{pg} / \mathrm{mg}^{(65)}$, the limit of detection in the Gambian study ${ }^{(52,53)}$. Week-16 adduct positivity correlated with the introduction of weaning foods, and by 52 weeks, most infants $(>95 \%)$ had started the weaning process. The week-16 and week-52 data reveal that aflatoxin from diet occurs early in life once weaning foods are introduced. The cord blood data reveal that both exposure and metabolism to reactive epoxides occurs in utero.

A cross-sectional survey of children aged 9-60 months from Benin revealed a 99\% positive rate (mean adduct level $33 \mathrm{pg} / \mathrm{mg}$; range non-detectable-1064 pg/mg); geometric mean aflatoxin biomarker levels were twice the level in 1 - and 2-year-olds compared with children $<1$ year old, and twice as high again in 2- and 3-yearolds $^{(48)}$. No significant increases were apparent in older children up to 5 years old. In two separate studies of Gambian children the frequency of detection and range of aflatoxin-albumin adducts were similar between 3- and 4 -year-olds (100\% positive; range $2-459 \mathrm{pg} / \mathrm{mg})^{(55)}$ and 6- to 9-year-olds (93\% positive; range non-detectable$456 \mathrm{pg} / \mathrm{mg})^{(54)}$ and such patterns of exposure reflect those observed in Gambian adults ${ }^{(47,53)}$. Exposure patterns between children (aged $>2$ years) and adults in Guinea were similar also ${ }^{(51,114-116)}$. Thus, there is a rapid increase in aflatoxin-albumin biomarker frequency and level as infants from high-risk countries go through the weaning process.

\section{Aflatoxin biomarker levels are associated with growth faltering}

A cross-sectional survey in Benin demonstrated a strong association between aflatoxin biomarker level (aflatoxinalbumin) and growth of children aged $<5$ years ${ }^{(48)}$. Growth was assessed as height-for-age and weight-for-age $Z$ scores. Both height-for-age and weight-for-age $Z$ scores were inversely associated with the aflatoxin exposure biomarker, indicative of a relationship between aflatoxin and both stunting and being underweight ( $P<0.001$ for both). A subsequent longitudinal study in infants from different villages, but from the same region, further support these cross-sectional observations ${ }^{(49)}$. These latter data suggested that across an exposure spectrum in which $16 \%$ of those infants measured exceeded an adduct burden of $100 \mathrm{pg} / \mathrm{mg}$ albumin, that $100 \mathrm{pg} / \mathrm{mg}$ difference in exposure approximates to about a $1 \mathrm{~cm}$ reduction in height over an 8-month period. In a separate study in slightly older Gambian children (aged 6-9 years), a more modest association between aflatoxin exposure and growth faltering was reported, though only $7 \%$ of samples in that study exceeded $100 \mathrm{pg} / \mathrm{mg}^{(54)}$. Thus, it remains unclear whether the strength of effect reflects differences by age, the adduct burden, or perhaps both.

In The Gambia, the average level of aflatoxin-albumin adducts in maternal blood during pregnancy (collected at two time points separated by $>1$ month) was strongly associated $(P<0.001)$ with growth faltering of the infant during the first year of life ${ }^{(52)}$. The aflatoxin-albumin adduct level of the infant at 16 weeks significantly negatively correlated $(P<0.05)$ with infant growth ${ }^{(52)}$. These studies are further supported by data in additional epidemiological studies ${ }^{(117,118)}$.

\section{Aflatoxin and gastrointestinal toxicity}

Growth faltering in West Africa does not seem to be fully explained by either lack of nutrition or by infectious episodes $^{(119-121)}$, though these remain critically important contributors. Growth faltering and intestinal damage in this region are apparent following the introduction of weaning foods and independently strong associations between aflatoxin and growth faltering, as described above $^{(48,49,52)}$ and elsewhere ${ }^{(122,123)}$, have been revealed. Human aflatoxin exposure is primarily through dietary contamination and, given the requisite metabolism to form the reactive epoxide, the intestine is a primary target for aflatoxin-induced damage. The intestinal epithelium separates the intestinal lumen from the underlying lamina propria. These epithelial cells are tightly bound by intercellular junctional complexes, which regulate the paracellular permeability, and thus maintain epithelial integrity. In confluent Caco- 2 monolayers, a cell line that mimics the intestinal barrier, aflatoxin appears to affect the integrity of the monolayer by modulating paracellular transport ${ }^{(124)}$. Thus, aflatoxin may further exacerbate dietary restricted individuals, and perhaps prolong a cycle of poor nutrient retention, extended gastrointestinal infection, and enteropathy. Intestinal enteropathy, often described as 'intestinal leakiness', is associated with the level of growth faltering in Gambian infants ${ }^{(119,120)}$, though to date dose-response relationships between intestinal enteropathy and aflatoxin load remain to be demonstrated. 
A variety of proteins are involved in the formation of intercellular functional complexes including tight junction complexes ${ }^{(125)}$. Tight junctions are in part regulated by specific phosphatases and kinases. Interactions between transmembrane proteins and the actomyosin ring are controlled by several signalling proteins, including protein kinase $\mathrm{C}$, mitogen-activated protein kinases, myosin light chain kinase and the Rho family of small GTPases ${ }^{(126)}$. Phosphorylation of tight junction proteins controls epithelial barrier function ${ }^{(126)}$. One of the key toxic effects of aflatoxin is disruption of phosphorylation patterns of structural and enzymic proteins, due to steric hindrance caused by the epoxide binding ${ }^{(127)}$. It is therefore plausible that the intestinal cell enteropathy observed in vitro reflects aflatoxin-induced disruption of the phosphorylation of key structural proteins in tight junction formation. To improve our understanding of this potential mechanism of growth faltering it will be valuable to understand aflatoxin-induced changes in tight junction protein localisation and phosphorylation status.

\section{Aflatoxin and zinc}

Human Zn deficiency has been a recognised health concern for about 50 years; typical symptoms include growth retardation, skin abnormalities and mental lethargy ${ }^{(128)}$. Dietary deficiency is a particular problem in developing countries, and a number of studies support supplementation of children aged $<5$ years to improve linear growth and reduce growth stunting ${ }^{(129)}$. In animal models, aflatoxins have a clear effect on growth, and it is notable that piglets of aflatoxin-exposed sows exhibit growth faltering ${ }^{(130)}$. One interesting observation is a reduced plasma $\mathrm{Zn}$ level in piglets from aflatoxin-exposed sows compared with those from non-exposed sows ${ }^{(131)}$; this was related to a reduced $Z$ n-carrying capacity due to thymulin-Zn complex formation in the offspring from exposed sows, rather than a lack of $\mathrm{Zn}$ in the diet ${ }^{(131)}$. Importantly, doses used in this animal study are in line with those observed in studies of maize for human consumption ${ }^{(23)}$. Thus, a second area of research into growth faltering in human subjects from regions with chronic and high aflatoxin exposure is to understand mechanisms that control the balance between inactive thymulin and active (Zn-bound) thymulin.

\section{Aflatoxin and insulin-like growth factor}

Aflatoxins can modulate gene expression in target organs including the liver. A number of growth factors are critical components in maintaining animal longitudinal growth. One such factor is liver-derived insulin-like growth factor (IGF)-1, which supplies at least $75 \%$ of IGF-1 in circulation. Locally produced IGF-1 also affects linear bone growth, though both local and liver-derived sources are believed to be important ${ }^{(132)}$. Microarray data comparing livers of untreated and aflatoxin-treated chicks revealed down-regulation of genes responsible for fatty acid metabolism, oxidative phosphorylation, energy production, cell proliferation, immune response, metabolism, growth and development in treated animals ${ }^{(133)}$ Of particular interest regarding growth was the down-regulation of IGF-1, which could have contributed to the observed reduction in growth rates in this particular study. This type of growth faltering was consistent with earlier reports of the effect of aflatoxins on broiler chick growth $^{(134)}$

Studies in children suggest a link between aflatoxin exposure and kwashiorkor, a form of protein malnutrition $^{(122,123)}$, though designs of this particular study were not ideal. Aflatoxin exposure was certainly occurring in those children; however, validated exposure biomarkers were not utilised, and thus dose-responses were not measurable. In one study, twenty-two children with proteinenergy malnutrition (either kwashiorkor $(n$ 9) or marasmus ( $n$ 13)) from Gabon aged $<30$ months were examined for their nutritional status with reference to the growth hormone-insulin-like growth factor axis ${ }^{(135)}$. Although aflatoxins were not measured, this region does experience chronic exposure to aflatoxins. In this study, IGF-1 was significantly lower in malnourished children compared with controls. These authors speculate that the change is related to the extent of malnutrition, as refeeding improved IGF-1 levels. However, no data were presented for a role for aflatoxin in this study, and IGF-1 levels may simply reflect poor growth, rather than exposure to aflatoxin; thus data on the temporal nature of aflatoxin exposure with this measure would be more informative. It has also been suggested that aflatoxin-induced up-regulation of IGF-2 may be important in hepatocarcinogenesis ${ }^{(136)}$; though IGF-2 does not play an important role in linear growth. At this point additional research is required to understand this hypothesised interaction between aflatoxin, the IGF axis and growth faltering.

\section{Fumonisin B, deoxynivalenol and growth faltering}

To date, there are no strong epidemiological data on links between Fusarium mycotoxins and child growth, though it is hoped that the use of biomarkers discussed above may allow improved exposure assessment to inform such studies. In cultured cells, prolonged exposure to $\mathrm{FB}_{1}$ has been demonstrated to reduce intestinal barrier integrity ${ }^{(137)}$, and to cause an increase in the ease of movement of macromolecules across the monolayer ${ }^{(138)}$. The mechanism(s) for such an effect remains unknown, though it is clearly established that fumonisins disrupt sphingolipid metabolism, key components in the integrity of the cell membranes ${ }^{(67,78)}$. A recent survey from Tanzania suggests an association between estimated FB consumption at age 6 months and the subsequent height and weight of the child at the age of 12 months ${ }^{(139)}$. The study included 
215 infants with maize consumption estimated for each child and the level of FB contamination in collected maize samples determined. Maize was consumed frequently ( $89 \%$ consumers) and $69 \%$ of the maizeconsuming infants were exposed to detectable levels of fumonisin; the range of fumonisins in maize was 21$3201 \mu \mathrm{g} / \mathrm{kg}$, and twenty-six infants were predicted to have exceeded the provisional maximum tolerable daily intake of $2 \mu \mathrm{g} / \mathrm{kg} \mathrm{BW}^{(80)}$. Infant height and weight were significantly negatively $(P<0.05)$ associated with estimated fumonisin intake. The authors identify a number of limitations in their study. First, there was no use of fumonisin exposure biomarkers. Second, exposure estimates were at 6 months but not 12 months. In that respect, it would also have been interesting to have data on growth velocity. It is notable that the co-occurrence of both aflatoxin and fumonisin contamination had been reported in an earlier survey of maize in this region ${ }^{(140)}$, and that aflatoxins and fumonisins also co-contaminate maize in Benin ${ }^{(10)}$, where strong associations between aflatoxin and growth faltering were reported $^{(48,49)}$. This research arena eagerly awaits descriptive epidemiology on multiple mycotoxin biomarker measurements to understand the potential causes and mechanisms of dietary contaminants and growth faltering in high-risk regions.

In contrast to the aflatoxins and fumonisins, the trichothecenes occur most frequently in cooler, moist conditions $^{(1,2)}$. Their global distribution thus differs from aflatoxin and fumonisins, predominantly in Europe, North America and parts of South America, China, Japan and New Zealand. DON is one of the most frequently observed trichothecenes found globally and the mechanism of toxicity is associated with its ability to inhibit ribosomal protein synthesis by restricting elongation and termination of polypeptide chains ${ }^{(19)}$. This ribosomal binding is responsible for DON's effect on the immune system, termed the 'ribotoxic stress response', which causes increased apoptosis in leucocytes and increased cytokine production $^{(141)}$.

Most instances of DON-induced feed refusal occur in experimental animals exposed to dietary $\mathrm{DON}^{(142-144)}$. However, pigs given an intraperitoneal infusion of DON also show reduced food intake of a DON-free diet ${ }^{(145)}$, suggesting that DON may affect food intake via a neuroendocrine mechanism. Indeed, pigs given an intravenous infusion of DON show increased levels of the serotonin metabolite 5-hydroxyindoleacetic acid in cerebral spinal fluid $^{(146)}$, although similar studies have found no changes in plasma serotonin levels ${ }^{(147)}$. DON can also cross into brain tissue ${ }^{(148)}$, and cause regional changes in the neurochemistry of pigs, turkeys and rats ${ }^{(149-151)}$.

Recent data from Girardet et al. ${ }^{(152)}$ suggest that DON acts centrally to reduce food intake. Here, a $20 \mu \mathrm{g}$ per mouse intracerebroventricular (ICV) injection of DON caused a significant reduction in food intake over a $12 \mathrm{~h}$ period. We point out that $2 \mu \mathrm{g}$ DON per mouse (weight of $0.020-0.025 \mathrm{~kg}$ ) is an approximate dose of $0.8-1.0 \mathrm{mg} / \mathrm{kg}$ BW and DON has been shown to cause acute anorexia when given via intraperitoneal injection at $1.0 \mathrm{mg} / \mathrm{kg} \mathrm{BW}$ in female mice ${ }^{(153)}$. Furthermore, Girardet et $a l^{(152)}$ determined that oral DON administration increased central protein expression of the transcription factor c-fos and mRNA expression of the pro-inflammatory mediators IL-1 $\beta$, TNF- $\alpha$, IL-6 and cyclo-oxygenase- 2 (COX-2), suggesting that DON does indeed cause physiological changes within the brain.

Given DON's capacity to elicit systemic pro-inflammatory cytokines and cause inflammation in vivo, it has been hypothesised that COX-2 may be important for DON's ability to cause anorexia and subsequent growth suppression in vivo $^{(154)}$. COX-2, along with microsomal PGE synthase-1 (mPGES-1), are two enzymes responsible for converting arachidonic acid into $\mathrm{PGE}_{2}$ during an inflammatory response ${ }^{(155)}$ and COX-2 has been shown to serve a function in anorexia caused by systemic inflammation ${ }^{(156,157)}$. Indeed, DON induces COX-2 gene expression in vitro (RAW 264.7 murine macrophages) and in vivo ${ }^{(158,159)}$, though the recent use of mPGES-1 knockout mice suggests that a $\mathrm{PGE}_{2}$-independent mechanism causes DON-induced anorexia $^{(152)}$.

Male and female mice fed 5 and 10 parts per million (ppm) DON over a 2-year period exhibit significant weight suppression ${ }^{(160)}$; yet, food intake was only significantly reduced in males fed $10 \mathrm{ppm}$ DON, indicating that anorexia may not be the only mechanism by which DON reduces weight. Recently, DON exposure in mice was associated with decreased IGF acid-labile subunit ${ }^{(161)}$, a binding protein of IGF-1 known to be critical for growth $^{(162,163)}$. DON-induced decreases in IGF acid-labile subunit may lead to alterations in the growth hormone system and subsequent growth suppression.

Taken together, growth suppression exhibited by experimental animals exposed to DON probably results from a combination of anorexia caused by alterations in neuroendocrine signalling and modifications of the growth hormone axis.

\section{Fumonisins and neural tube defects}

Fumonisins have been demonstrated to cause NTD in animals ${ }^{(164-166)}$, and given the frequency and high levels of exposure in certain maize-consuming populations in South Africa, Central America and Asia, there are concerns of similar effects in humans. For example, women living in Cameron County, Texas-Mexico border had NTD incidence of 290 per 100 000, whilst Mexican Americans in general have NTD incidence of $90-160$ per 100000 ; this is a significantly higher frequency compared with white Caucasians $(60 \text { per } 100000)^{(167)}$. Sphingolipids are important structural components in cell membranes, and fumonisin disruption of sphingolipid biosynthesis interferes with folate receptors, and thus folate bioavailability ${ }^{(164,168)}$. 
In a study conducted in pregnant mice, fumonisin given during early gestation caused NTD in $79 \%$ of exposed fetuses. Alterations in sphingolipid profiles for both maternal and embryonic tissues occurred, as did both the folate concentration and expression of the folate receptor $^{(164)}$. Of note in this study was that folate supplementation partially reduced the phenotype of NTD; although the dose level was relatively high, these observations raise some concern for humans chronically exposed to fumonisins.

An increased risk of NTD was significantly associated (OR 2.4; 95\% CI 1.1, 5.3) with moderate compared with low consumption of tortillas in the first trimester of pregnancy for women on the Texas-Mexico border ${ }^{(164)}$. Fumonisins are common contaminants of maize in this region, and maize consumption in the form of tortillas forms a major dietary staple. To better assess fumonisin exposure, maternal sphingolipid disruption (measured as the ratio of plasma sphinganine:sphingosine) and estimated FB consumption based on a limited food survey with FB measurements were determined. Both of these measures followed a similar pattern, with an increased risk of NTD between low and moderate groups, but not with the high exposure group. The authors suggest a threshold effect was possible, above which live births may not be occurring. It is important to note that the sphinganine:sphingosine measure was taken some time after birth (weeks), though the authors suggest that diets, and therefore exposure patterns, do not change much. More critical is the fact that sphinganine:sphingosine remains a putative but, to date, unvalidated exposure biomarker. NTD represent a significant health burden in maizeconsuming populations where fumonisin exposure is frequent and at high levels. The animal and epidemiological data strongly support a role for this dietary toxin in increasing the risk of NTD through changes in folate receptor activity. Authors of the above studies highlight the desire for better exposure assessment tools to evaluate the temporal variation of fumonisins during critical exposure periods.

\section{Fusarium mycotoxins and cancer}

The incidence of squamous-cell carcinomas of the oesophagus (SCCO) is particularly high in parts of China, Iran and South Africa $^{(23)}$. China reports about $50 \%$ of all SCCO cases, with incidence rates in Lixian county as high as 151 and 115 per 100000 for males and females, respectively. At-risk populations are typically maize consumers, and Fusarium mycotoxins, for example, fumonisins and trichothecenes (DON, nivalenol), frequently contaminate maize in these regions. Ecological surveys examining the differences in the natural occurrence of Fusarium mycotoxins in high-risk regions of both China and South Africa are suggestive of a link with SCCO, and in vitro and animal data provide additional support ${ }^{(169-174)}$, though no biomarker-driven epidemiology is available at this point. Fumonisins cause cancer in the liver and kidneys in rodents ${ }^{(175)}$. Whilst $\mathrm{FB}_{1}$ has been classified by the International Agency for Research on Cancer (IARC) ${ }^{(23)}$ as class 2B (possibly carcinogenic), data for DON are insufficient. Exposure biomarkers to Fusarium mycotoxins should support an improved understanding of their potential role in SCCO.

\section{Conclusions}

Mycotoxins are frequent contaminants of the diet in all locations of the world that consume cereals, and additional exposure from nuts predominates in some countries; in fact, $25 \%$ of the world's cereal crops are predicted to be contaminated $^{(1)}$. In animals, toxicity is clearly established. Aflatoxins are carcinogenic, affect the immune systems and cause growth faltering. Moreover, aflatoxins cause immune suppression and increased susceptibility to infection. There is moderate evidence that they cause disruption to tight junctions and thus exposure may mimic the intestinal enteropathy observed in growth-faltering children. Fumonisins disrupt cell-cell communications and cell integrity via a mechanism linked to sphingolipid biosynthesis disruption; they also cause liver and kidney cancers in rodents, and in rodents cause NTD and intestinal toxicity. DON has potent effects on the immune system, causes gastroenteritis, anorexia and growth faltering in animals, though biomarker-driven epidemiology is lacking.

The present review has highlighted a number of areas including:

(1) Established exposure biomarkers for the carcinogenic aflatoxins.

(2) Biomarkers to assess the suggested role of aflatoxin in growth faltering.

(3) Potential mechanisms of mycotoxin-induced growth faltering.

(4) Recent development and the need for Fusarium biomarkers for epidemiology.

Intervention strategies to restrict exposure to aflatoxins have been recently reviewed ${ }^{(22)}$. Notable examples include intervention research in China that has focused on chemoprevention $^{(22)}$, whilst a Novacil clay that can be added in small quantities to food and act to bind and restrict the bioavailability of aflatoxin has been reported in clinical trials conducted in West Africa ${ }^{(176)}$. In middle-income countries or regions where exposures may be more moderate, probiotic interventions have been suggested ${ }^{(177)}$; these probiotics restrict aflatoxin bioavailability by binding and then shuttling the toxin through the gastrointestinal tract. Such an approach has been suggested as plausible in a region such as Egypt ${ }^{(178)}$ where sources of exposure are less well defined ${ }^{(26,27,60)}$. In terms of growth, this approach was successful in a rodent model in that in the intervention arm, both the aflatoxin-driven growth 
faltering was improved and the aflatoxin biomarker level was reduced ${ }^{(179)}$. Whilst effective but highly technical approaches are used in wealthier regions, the small-scale peasant farmers, who represent the majority of those at highest risk of exposure, still remain without established, affordable and sustainable methods to restrict exposures. A primary intervention in such populations successfully restricted contamination at the harvest/post-harvest stage by simple sorting and drying of the main $\mathrm{crops}^{(111)}$. The study focused on aflatoxin from the groundnut (peanut) crop in Guinea, and demonstrated over a 6-month period a significant $(P<0.001)$ reduction in aflatoxin biomarkers, by $>50 \%$, in the intervention villages. Such an approach is simple and relatively affordable. It is now important to demonstrate efficacy in different settings and with other high-risk crops such as maize. Dissemination and application of this and other intervention data, in an appropriate manner is then urgently required ${ }^{(180)}$, such that the research efforts are translated into the community settings where risk is greatest.

It is also important to note that we believe that whilst evidence for aflatoxin 'contributing' to growth faltering is strong, this occurs alongside a background of additional factors, including limited nutritional quantity and choice, and infection. Thus, one postulated mechanism is that aflatoxin exacerbates pathologies important in intestinal enteropathy-driven growth faltering. Other mechanisms related to aflatoxin toxicity discussed here remain poorly researched. The molecular epidemiology for other mycotoxins is lacking, but exposure biomarkers may better support current epidemiological approaches to assess the potential burden of mycotoxin-driven chronic disease.

\section{Acknowledgements}

This research received no specific grant from any funding agency in the public, commercial or not-for-profit sectors. All authors contributed to writing the manuscript. There are no conflicts of interest.

\section{References}

1. Council for Agricultural Science and Technology (CAST) (2003) Potential economic costs of mycotoxins in the United States. In Mycotoxins: Risks in Plant, Animal and Human Systems, Task Force report no. 139, pp. 136-142. Ames, IA: CAST.

2. Miller JD (1995) Fungi and mycotoxins in grain: implications for stored product research. J Stored Prod Res 31, $1-16$.

3. Miraglia M, Marvin HJ, Kleter GA, et al. (2009) Climate change and food safety: an emerging issue with special focus on Europe. Food Chem Toxicol 47, 1009-1021.

4. Bennett JW \& Klich M (2003) Mycotoxins. Clin Microbiol Rev 16, 497-516.

5. Williams JH, Phillips TD, Jolly PE, et al. (2005) Human aflatoxicosis in developing countries: a review of toxicology, exposure, potential health consequences, and interventions. Am J Clin Nutr 80, 1106-1122.

6. Wild CP \& Turner PC (2002) The toxicology of aflatoxins as a basis for public health decisions. Mutagenesis 17, 471-481.

7. Marasas WFO (2001) Discovery, occurrence of the fumonisins, a historical perspective. Environ Health Perspect 109, Suppl. 2, 239-243.

8. Sun G, Wang S, Hu X, et al. (2011) Co-contamination of aflatoxin $\mathrm{B}_{1}$ and fumonisin $\mathrm{B}_{1}$ in food and human dietary exposure in three areas of China. Food Addit Contam Part A Chem Anal Control Expo Risk Assess 28, 461-470.

9. Rocha LO, Nakai VK, Braghini R, et al. (2009) Mycoflora and co-occurrence of fumonisins and aflatoxins in freshly harvested corn in different regions of Brazil. Int J Mol Sci 10, 5090-5103.

10. Kimanya ME, De Meulenaer B, Tiisekwa B, et al. (2008) Cooccurrence of fumonisins with aflatoxins in home-stored maize for human consumption in rural villages of Tanzania. Food Addit Contam Part A Chem Anal Control Expo Risk Assess 25, 1353-1364.

11. Sangare-Tigori B, Moukha S, Kouadio HJ, et al. (2006) Cooccurrence of aflatoxin $\mathrm{B}_{1}$, fumonisin $\mathrm{B}_{1}$, ochratoxin $\mathrm{A}$ and zearalenone in cereals and peanuts from Côte d'Ivoire. Food Addit Contam 23, 1000-1007.

12. Park JW, Kim EK, Shon DH, et al. (2002) Natural cooccurrence of aflatoxin $\mathrm{B}_{1}$, fumonisin $\mathrm{B}_{1}$ and ochratoxin A in barley and corn foods from Korea. Food Addit Contam 19, 1073-1080.

13. Vargas EA, Preis RA, Castro L, et al. (2001) Co-occurrence of aflatoxins $B_{1}, B_{2}, G_{1}, G_{2}$, zearalenone and fumonisin $B_{1}$ in Brazilian corn. Food Addit Contam 18, 981-986.

14. Kpodo K, Thrane U \& Hald B (2000) Fusaria and fumonisins in maize from Ghana and their co-occurrence with aflatoxins. Int J Food Microbiol 61, 147-157.

15. González HH, Martínez EJ, Pacin AM, et al. (1999) Natural co-occurrence of fumonisins, deoxynivalenol, zearalenone and aflatoxins in field trial corn in Argentina. Food Addit Contam 16, 565-569.

16. Ali N, Sardjono, Yamashita A, et al. (1998) Natural co-occurrence of aflatoxins and Fusarium mycotoxins (fumonisins, deoxynivalenol, nivalenol and zearalenone) in corn from Indonesia. Food Addit Contam 15, 377-384.

17. Yoshizawa T, Yamashita A \& Chokethaworn N (1996) Occurrence of fumonisins and aflatoxins in corn from Thailand. Food Addit Contam 13, 163-168.

18. Wang DS, Liang YX, Nguyen TC, et al. (1995) Natural cooccurrence of Fusarium toxins and aflatoxin $\mathrm{B}_{1}$ in corn for feed in north Vietnam. Nat Toxins 3, 445-449.

19. Rotter BA, Prelusky DB \& Pestka JJ (1996) Toxicology of deoxynivalenol (vomitoxin). J Toxicol Environ Health $\mathbf{4 8}$, $1-34$.

20. Brera C \& Miraglia M (2003) SCOOP Report: Collection of Occurrence Data of Fusarium Toxins in Food and Assessment of Dietary Intake by the Population of EU Member States. Brussels: European Commission.

21. Wild CP \& Turner PC (2001) Exposure biomarkers in chemoprevention studies of liver cancer. In Biomarkers in Cancer Chemoprevention, IARC Scientific Publication no. 154, pp. 215-222 [AB Millar, H Bartsch, P Boffetta, L Dragsted and H Vainio, editors]. Lyon: IARC.

22. Kensler TW, Roebuck BD, Wogan GN, et al. (2011) Aflatoxin: a 50 year odyssey of mechanistic and translational toxicology. Toxicol Sci 120, Suppl. 1, S28-S48.

23. International Agency for Research on Cancer (1993) Some Naturally Occurring Substances: Food Items and Constituents, 
Heterocyclic Aromatic Amines and Mycotoxins, vol. 56, IARC Monograph. Lyon: IARC.

24. Eaton DL, Ramsdell HS \& Neal GE (1994) Biotransformation of the aflatoxins. In The Toxicology of Aflatoxins: Human Health, Veterinary and Agricultural Significance, pp. 45-72 [DL Eaton and JD Groopman, editors]. San Diego: Academic Press.

25. Zarba A, Wild CP, Hall AJ, et al. (1992) Aflatoxin $M_{1}$ in human breast milk from The Gambia, West Africa, quantified by combined monoclonal antibody immunoaffinity chromatography and HPLC. Carcinogenesis 13, 891-894.

26. Polychronaki N, West RM, Turner PC, et al. (2007) A longitudinal assessment of aflatoxin $\mathrm{M}_{1}$ excretion in breast milk of selected Egyptian mothers. Food Chem Toxicol 45, 1210-1215.

27. Polychronaki N, Turner PC, Mykkänen H, et al. (2006) Determinants of aflatoxin $\mathrm{M}_{1}$ in breast milk of Egyptian mothers. Food Add Contam 23, 700-708.

28. Guengerich FP, Ueng YF, Kim BR, et al. (1996) Activation of toxic chemicals by cytochrome P450 enzymes: regio- and stereoselective oxidation of aflatoxin $\mathrm{B}_{1}$. Adv Exp Med Biol 387, 7-15.

29. Gallagher EP, Kunze KL, Stapleton PL, et al. (1996) The kinetics of aflatoxin $\mathrm{B}_{1}$ oxidation by human cDNA-expressed and human liver microsomal cytochromes P450 1A2 and 3A4. Toxicol Appl Pharmacol 141, 595-606.

30. Raney VM, Harris TM \& Stone MP (1993) DNA conformation mediates aflatoxin $\mathrm{B}_{1}$-DNA binding and the formation of guanine N7 adducts by aflatoxin $B_{1}$ 8,9-exo-epoxide. Chem Res Toxicol 6, 64-68.

31. Polychronaki N, Wild CP, Mykkänen H, et al. (2008) Urinary biomarkers of aflatoxin exposure in young children from Egypt and Guinea. Food Chem Toxicol 46, 519-526.

32. Jonsyn-Ellis FE (2001) Seasonal variation in exposure frequency and concentration levels of aflatoxins and ochratoxins in urine samples of boys and girls. Mycopathologia 152, $35-40$.

33. Groopman JD, Wild CP, Hasler J, et al. (1993) Molecular epidemiology of aflatoxin exposures: validation of aflatoxin-N7-guanine levels in urine as a biomarker in experimental rat models and humans. Environ Health Perspect 99, 107-113.

34. Groopman JD, Hall A, Whittle H, et al. (1992) Molecular dosimetry of aflatoxin-N7-guanine in human urine obtained in The Gambia, West Africa. Cancer Epidemiol Biomarkers Prev 1, 221-228.

35. Groopman JD, Zhu JQ, Donahue PR, et al. (1992) Molecular dosimetry of urinary aflatoxin-DNA adducts in people living in Guangxi Autonomous Region, People's Republic of China. Cancer Res 52, 45-52.

36. Zhu JQ, Zhang LS, Hu X, et al. (1987) Correlation of dietary aflatoxin $\mathrm{B}_{1}$ levels with excretion of aflatoxin $\mathrm{M}_{1}$ in human urine. Cancer Res 47, 1848-1852.

37. Sabbioni G, Skipper PL, Büchi G, et al. (1987) Isolation and characterization of the major serum albumin adduct formed by aflatoxin $\mathrm{B}_{1}$ in vivo in rats. Carcinogenesis $\mathbf{8}$, 819-824.

38. Sabbioni G, Ambs S, Wogan GN, et al. (1990) The aflatoxin-lysine adduct quantified by high-performance liquid chromatography from human serum albumin samples. Carcinogenesis 11, 2063-2066.

39. Gan LS, Skipper PL, Peng XC, et al. (1988) Serum albumin adducts in the molecular epidemiology of aflatoxin carcinogenesis: correlation with aflatoxin $\mathrm{B}_{1}$ intake and urinary excretion of aflatoxin $\mathrm{M}_{1}$. Carcinogenesis 9, 1323-1325.

40. Anwar WA, Khalil MM \& Wild CP (1994) Micronuclei, chromosomal aberrations and aflatoxin-albumin adducts in experimental animals after exposure to aflatoxin $B_{1}$. Mutat Res 322, 61-67.

41. Wild CP, Hasegawa R, Barraud L, et al. (1996) Aflatoxinalbumin adducts: a basis for comparative carcinogenesis between animals and humans. Cancer Epidemiol Biomarkers Prev 5, 179-189.

42. Wild CP, Jiang YZ, Sabbioni G, et al. (1990) Evaluation of methods for quantitation of aflatoxin-albumin adducts and their application to human exposure assessment. Cancer Res 50, 245-251.

43. Wild CP, Hudson GJ, Sabbioni G, et al. (1992) Dietary intake of aflatoxins and the level of albumin-bound aflatoxin in peripheral blood in The Gambia, West Africa. Cancer Epidemiol Biomarkers Prev 1, 229-234.

44. Wild CP, Jiang YZ, Allen SJ, et al. (1990) Aflatoxin-albumin adducts in human sera from different regions of the world. Carcinogenesis 11, 2271-2274.

45. Wild CP, Rasheed FN, Jawla MF, et al. (1990) In utero exposure to aflatoxin in West Africa. Lancet 337, 1602.

46. Allen SJ, Wild CP, Wheeler JG, et al. (1992) Aflatoxin exposure, malaria and hepatitis B infection in rural Gambian children. Trans Royal Soc Trop Med Hyg 86, 426-430.

47. Wild CP, Yin F, Turner PC, et al. (2000) Environmental and genetic determinants of aflatoxin-albumin adducts in The Gambia. Int J Cancer 86, 1-7.

48. Gong YY, Cardwell K, Hounsa A, et al. (2002) Dietary aflatoxin exposure and impaired growth in young children from Benin and Togo, West Africa: cross sectional study. Br Med J 325, 20-21.

49. Gong YY, Hounsa A, Egal S, et al. (2004) Post-weaning exposure to aflatoxin results in impaired child growth: a longitudinal study in Benin, West Africa. Environ Health Perspect 112, 1334-1338.

50. Shuaib FM, Jolly PE, Ehiri JE, et al. (2010) Association between anemia and aflatoxin $\mathrm{B}_{1}$ biomarker levels among pregnant women in Kumasi, Ghana. Am J Trop Med Hyg 83, $1077-1083$.

51. Turner PC, Sylla A, Kuang SY, et al. (2005) Absence of TP53 codon 249 mutations in Guinean infants with high aflatoxin exposure. Cancer Epidemiol Biomarkers Prev 14, 2053-2055

52. Turner PC, Collinson AC, Cheung YB, et al. (2007) Aflatoxin exposure in utero causes growth faltering in Gambian infants. Int J Epidemiol 36, 1119-1125.

53. Turner PC, Van Der Westhuizen L \& Nogueira Da Costa A (2011) Biomarkers of exposure: mycotoxins - aflatoxin, deoxynivalenol and fumonisins. In Biomarkers and Human Biomonitoring, pp. 50-86 [LE Knudsen and DF Merlo, editors]. Cambridge: Royal Society of Chemistry.

54. Turner PC, Moore SE, Hall AJ, et al. (2003) Modification of immune function through exposure to dietary aflatoxin in Gambian children. Environ Health Persp 111, 217-220.

55. Turner PC, Mendy M, Whittle H, et al. (2000) Hepatitis B infection and aflatoxin biomarker levels in Gambian children. Trop Med Int Health 5, 837-841.

56. Ahsan H, Wang LY, Chen CJ, et al. (2001) Variability in aflatoxin-albumin adduct levels and effects of hepatitis B and $\mathrm{C}$ virus infection and glutathione S-transferase M1 and T1 genotype. Environ Health Persp 109, 833-837.

57. Wang P, Afriyie-Gyawu E, Tang Y, et al. (2008) NovaSil clay intervention in Ghanaians at high risk for aflatoxicosis: II. Reduction in biomarkers of aflatoxin exposure in blood and urine. Food Addit Contam Part A Chem Anal Control Expo Risk Assess 25, 622-634.

58. Wang JS, Qian GS, Zarba A, et al. (1996) Temporal patterns of aflatoxin-albumin adducts in hepatitis B surface antigenpositive and antigen-negative residents of Daxin, Qidong 
County, People's Republic of China. Cancer Epidemiol Biomarkers Prev 5, 253-261.

59. Kensler TW, He X, Otieno M, et al. (1988) Oltipraz chemoprevention trial in Qidong, People's Republic of China: modulation of serum aflatoxin albumin adduct biomarkers. Cancer Epidemiol Biomarkers Prev 7, 127-134.

60. Turner PC, Loffredo C, El-Kafrawy S, et al. (2008) A survey of aflatoxin-albumin adducts in sera from Egypt. Food Add Contam 5, 583-587.

61. Scussel VM, Haas P, Gong Y, et al (2006) Study of aflatoxin exposure in a Brazilian population using an aflatoxin-albumin biomarker. In Mycotoxins and Phycotoxins: Advances in Determination, Toxicology and Exposure Management, pp. 197-202 [H Njapau, S Trujillo, HP van Egmond and DL Park, editors]. Wageningen: Wageningen Academic Publishers.

62. Scholl PF \& Groopman JD (2008) Long-term stability of human aflatoxin $\mathrm{B}_{1}$ albumin adducts assessed by isotope dilution mass spectrometry and high-performance liquid chromatography-fluorescence. Cancer Epidemiol Biomarkers Prev 17, 1436-1439.

63. McCoy LF, Scholl PF, Sutcliffe AE, et al. (2008) Human aflatoxin albumin adducts quantitatively compared by ELISA, HPLC with fluorescence detection, and HPLC with isotope dilution mass spectrometry. Cancer Epidemiol Biomarkers Prev 17, 1653-1657.

64. Scholl PF, Turner PC, Sutcliffe AE, et al. (2006) Quantitative comparison of aflatoxin $B_{1}$ serum albumin adducts in humans by isotope dilution mass spectrometry and ELISA. Cancer Epidemiol Biomarkers Prev 15, 823-826.

65. Johnson NM, Qian G, Xu L, et al. (2010) Aflatoxin and PAH exposure biomarkers in a U.S. population with a high incidence of hepatocellular carcinoma. Sci Total Environ 408, 6027-6031.

66. Shephard GS, Marasas WFO, Burger HM, et al. (2007) Exposure assessment for fumonisins in the former Transkei region of South Africa. Food Add Contam 24, 621-629.

67. Merrill AH Jr, Wang E, Vales TR, et al. (1996) Fumonisin toxicity and sphingolipid biosynthesis. Adv Exp Med Biol 392 , 297-306.

68. Shephard GS, Thiel PG \& Sydenham EW (1992) Initial studies on the toxicokinetics of fumonisin $\mathrm{B}_{1}$ in rats. Food Chem Toxicol 30, 277-279.

69. Prelusky DB, Miller JD \& Trenholm HL (1996) Disposition of ${ }^{14} \mathrm{C}$-derived residues in tissues of pigs fed radiolabelled fumonisin $\mathrm{B}_{1}$. Food Add Contam 13, 155-162.

70. Norred WP, Plattner RD \& Chamberlain WJ (1993) Distribution and excretion of ${ }^{14} \mathrm{C}$-fumonisin $\mathrm{B}_{1}$ in male Sprague-Dawley rats. Nat Toxins 1, 341-346.

71. Shephard GS, Thiel PG, Sydenham EW, et al. (1992) Fate of a single dose of the ${ }^{14} \mathrm{C}$-labelled mycotoxin, fumonisin $\mathrm{B}_{1}$, in rats. Toxicon 30, 768-770.

72. Shephard GS, Thiel PG, Sydenham EW, et al. (1994) Distribution and excretion of a single dose of the mycotoxin fumonisin $\mathrm{B}_{1}$ in a non-human primate. Toxicon 32, 735-741.

73. Dilkin P, Direito G, Simas MM, et al. (2010) Toxicokinetics and toxicological effects of single oral dose of fumonisin $\mathrm{B}_{1}$ containing Fusarium verticillioides culture material in weaned piglets. Chem Biol Interact 185, 157-162.

74. Van der Westhuizen L, Shephard GS \& Van Schalkwyk DJ (2001) The effect of repeated gavage doses of fumonisin $\mathrm{B}_{1}$ on the sphinganine and sphingosine levels in vervet monkeys. Toxicon 39, 969-972.

75. Riley RT, An NH, Showker JL, et al. (1993) Alteration of tissue and serum sphinganine to sphingosine ratio, an early biomarker for exposure to fumonisin-containing feeds in pigs. Toxicol Appl Pharmacol 118, 105-112.

76. Shephard GS, Van der Westhuizen L \& Sewram V (2007) Biomarkers of exposure to fumonisin mycotoxins: a review. Food Add Contam 24, 1196-1201.

77. Turner PC, Nikiema P \& Wild CP (1999) Fumonisin contamination of food: progress in development of biomarkers to better assess human health risks. Mutat Res 443, 81-93.

78. Merrill AH Jr, Sullards MC, Wang E, et al. (2001) Sphingolipid metabolism, roles in signal transduction and disruption by fumonisins. Environ Health Persp 109, Suppl. 2, 283-289.

79. Gong YY, Torres-Sanchez L, Lopez-Carrillo L, et al. (2008) Association between tortilla consumption and human urinary fumonisin $\mathrm{B}_{1}$ levels in a Mexican population. Cancer Epidemiol Biomarkers Prev 17, 688-694.

80. Food and Agriculture Organizion \& World Health Organization Joint $\mathrm{FAO} / \mathrm{WHO}$ expert committee on food additives. Sevenety-fourth meeting Rome, 14-23 June 2011, Summary and Conclusions. ftp://ftp.fao.org/ag/agn/jecfa/JECFA_74_Summary_Report_4July2011.pdf (accessed 11 November 2011).

81. Xu L, Cai Q, Tang L, et al. (2010) Evaluation of fumonisin biomarkers in a cross-sectional study with two high-risk populations in China. Food Addit Contam Part A Chem Anal Control Expo Risk Assess 27, 1161-1169.

82. van der Westhuizen L, Shephard GS, Burger HM, et al. (2011) Fumonisin $B_{1}$ as a urinary biomarker of exposure in a maize intervention study among South African subsistence farmers. Cancer Epidemiol Biomarkers Prev 20, 483-489.

83. Riley RT (2009) The kinetics of urinary fumonisin excretion in humans consuming maize-based foods. Toxicol Sci 114, Suppl. 1, 308-309.

84. Desalegn B, Nanayakkara S, Harada KH, et al. (2011) Mycotoxin detection in urine samples from patients with chronic kidney disease of uncertain etiology in Sri Lanka. Bull Environ Contam Toxicol 87, 6-10.

85. Zitomer NC \& Riley RT (2011) Extraction and analysis of fumonisins and compounds indicative of fumonisin exposure in plant and mammalian tissues and cultured cells. Methods Mol Biol 739, 171-185.

86. Pestka JJ \& Smolinski AT (2005) Deoxynivalenol: toxicology and potential effects on humans. J Toxicol Env Health-Pt BCrit Rev 8, 39-69.

87. He P, Young LG \& Forsberg C (1992) Microbial transformation of deoxynivalenol (vomitoxin). Appl Environ Microbiol 58, 3857-3863.

88. Seeling K, Danicke S, Valenta H, et al. (2006) Effects of Fusarium toxin-contaminated wheat and feed intake level on the biotransformation and carry-over of deoxynivalenol in dairy cows. Food Add Contam 23, 1008-1020.

89. Yoshizawa T, Cote LM, Swanson SP, et al. (1986) Confirmation of DOM-1, a de-epoxidation metabolite of deoxynivalenol, in biological-fluids of lactating cows. Agric Biol Chem 50, 227-229.

90. Young JC, Zhou T, Yu H, et al. (2007) Degradation of trichothecene mycotoxins by chicken intestinal microbes. Food Chem Toxicol 45, 136-143.

91. Eriksen GS \& Pettersson H (2003) Lack of de-epoxidation of type B trichothecenes in incubates with human faeces. Food Add Contam 20, 579-582.

92. Meky FA, Turner PC, Ashcroft AE, et al. (2003) Development of a urinary biomarker of human exposure to deoxynivalenol. Food Chem Toxicol 41, 265-273.

93. Turner PC, Burley VJ, Rothwell JA, et al. (2008) Dietary wheat reduction decreases the level of urinary 
deoxynivalenol in UK adults. $J$ Exp Sci Environ Epidemiol 18, 392-399.

94. Turner PC, Rothwell JA, White KLM, et al. (2008) Urinary deoxynivalenol is correlated with cereal intake in individuals from the United Kingdom. Environ Health Persp 116, 21-25.

95. Turner PC, White KLM, Burley V, et al. (2010) A comparison of deoxynivalenol intake and urinary deoxynivalenol in UK adults. Biomarkers 15, 553-562.

96. Turner PC, Hopton RP, Lecluse Y, et al. (2010) Determinants of urinary deoxynivalenol and de-epoxy deoxynivalenol in male farmers from Normandy, France. J Agric Food Chem 58, 5206-5212.

97. Hepworth SJ, Hardie LJ, Fraser LK, et al. (2012) Deoxynivalenol exposure assessment in a cohort of pregnant women from Bradford, UK. Food Add Contam Part A Chem Anal Control Expo Risk Assess 29, 269-276.

98. Turner PC, Hopton R, White KL, et al. (2011) Assessment of deoxynivalenol metabolite profiles in UK adults. Food Chem Toxicol 49, 132-135.

99. Turner PC, Burley VJ, Rothwell JA, et al. (2008) Deoxynivalenol: rationale for development and application of a urinary biomarker. Food Add Contam 25, 864-871.

100. Turner PC (2010) Deoxynivalenol and nivalenol occurrence and exposure assessment. World Mycotoxin J 3, 315-321.

101. Turner PC, Ji BT, Shu XO, et al. (2011) A biomarker survey of urinary deoxynivalenol in China: the Shanghai Women's Health Study. Food Add Contam Part A Chem Anal Control Expo Risk Assess 28, 1220-1223.

102. Turner PC, Taylor EF, White KLM, et al. (2009) A comparison of $24 \mathrm{~h}$ urinary deoxynivalenol with recent $v$. average cereal consumption for UK adults. Br J Nutr 102, $1276-1279$.

103. Warth B, Sulyok M, Berthiller F, et al. (2011) Direct quantification of deoxynivalenol glucuronide in human urine as biomarker of exposure to the Fusarium mycotoxin deoxynivalenol. Anal Bioanal Chem 401, 195-200.

104. Scientific Committee on Food (2002) Opinion of the Scientific Committee on Food on Fusarium toxins Part 6: Group evaluation of T-2 toxin, HT-2 toxin, nivalenol and deoxynivalenol: 2002SCF/CS/CNTM/MYC/27. http://europa.eu.int/ comm/food/fs/sc/scf/out123_en.pdf (accessed June 2011).

105. Rubert J, Soriano JM, Mañes J, et al. (2011) Rapid mycotoxin analysis in human urine: a pilot study. Food Chem Toxicol 49, 2299-2304.

106. Lattanzio VM, Solfrizzo M, De Girolamo A, et al. (2011) LC-MS/MS characterization of the urinary excretion profile of the mycotoxin deoxynivalenol in human and rat. J Chromatogr B Analyt Technol Biomed Life Sci 879 , 707-715.

107. Gilbert J, Brereton P \& MacDonald S (2001) Assessment of dietary exposure to ochratoxin A in the UK using a duplicate diet approach and analysis of urine and plasma samples. Food Add Contam 18, 1088-1093.

108. Liu Y \& Wu F (1990) Global burden of aflatoxin-induced hepatocellular carcinoma: a risk assessment. Environ Health Perspect 118, 818-824.

109. Wogan GN, Kensler TW \& Groopman JD (2012) Present and future directions of translational research on aflatoxin and hepatocellular carcinoma. A review. Food Addit Contam Part A Chem Anal Control Expo Risk Assess 29, 249-257.

110. Gong YY, Turner PC, Hall AJ, et al (2008) Aflatoxin exposure and impaired child growth in West Africa: an unexplored international public health burden? In Mycotoxins Detection Methods, Management, Public Health and
Agricultural Trade, pp. 53-66 [J Leslie, R Bandyopadhyay and A Visconti, editors]. Wallingford: CABI.

111. Turner PC, Sylla A, Gong YY, et al. (2005) Reduction in exposure to carcinogenic aflatoxins by postharvest intervention measures in West Africa: a community-based intervention study. Lancet 365, 1950-1956.

112. Bondy GS \& Pestka JJ (2003) Immunomodulation by fungal toxins. J Toxicol Env Health B Crit Rev 3, 109-143.

113. Dersjant-Li Y, Verstegen MWA \& Gerrits WJJ (2003) The impact of low concentrations of aflatoxin, deoxynivalenol or fumonisin in diets on growing pigs and poultry. Nutr Res Rev 16, 223-239.

114. Turner PC, Sylla A, Diallo MS, et al. (2002) The role of aflatoxins and hepatitis viruses in the etiopathogenesis of hepatocellular carcinoma: a basis for primary prevention in Guinea-Conakry, West Africa. J Gastroenterol Hepatol 17, Suppl., S441-S448.

115. Sylla A, Diallo MS, Castegnaro J, et al. (1999) Interactions between hepatitis B virus infection and exposure to aflatoxins in the development of hepatocellular carcinoma: a molecular epidemiological approach. Mutat Res 428, 187-196.

116. Diallo MS, Sylla A, Sidibé K, et al. (1995) Prevalence of exposure to aflatoxin and hepatitis B and $\mathrm{C}$ viruses in Guinea, West Africa. Nat Toxins 3, 6-9.

117. Abdulrazzaq YM, Osman N \& Yousif ZM (2004) Morbidity in neonates of mothers who have ingested aflatoxins. Ann Trop Paed 24, 145-151.

118. Abdulrazzaq YM, Osman N, Ibrahim A, et al. (2002) Fetal exposure to aflatoxins in the United Arab Emirates. Ann Trop Paediatr 22, 3-9.

119. Campbell DI, Elia M \& Lunn PG (2003) Growth faltering in rural Gambian infants is associated with impaired small intestinal barrier function, leading to endotoxemia and systemic inflammation. J Nutr 133, 1332-1338.

120. Lunn PG, Northro-Clewes CA \& Downes RM (1991) Intestinal permeability, mucosal injury, and growth faltering in Gambian infants. Lancet 338, 907-910.

121. Prentice A (1993) Nutrient requirements for growth, pregnancy and lactation: the Keneba experience. $S$ Afr J Clin Nutr 6, 33-38.

122. Tchana AN, Moundipa PF \& Tchouanguep FM (2010) Aflatoxin contamination in food and body fluids in relation to malnutrition and cancer status in Cameroon. Int J Environ Res Pub Health 7, 178-188.

123. Hendrickse RG (1988) Kwashiorkor and aflatoxins. J Ped Gastroenterol Nutr 7, 633-636.

124. Gratz S, Wu QK, El-Nezami H, et al. (2007) Lactobacillus rhamnosus strain GG reduces aflatoxin $\mathrm{B}_{1}$ transport, metabolism, and toxicity in Caco-2 cells. Appl Environm Microbiol 73, 3958-3964.

125. Madara JL (1998) Regulation of the movement of solutes across tight junctions. Annu Rev Physiol 60, 143-159.

126. Ulluwishewa D, Anderson RC, McNabb WC, et al. (2011) Regulation of tight junction permeability by intestinal bacteria and dietary components. J Nutr 141, 769-776.

127. Cullen JM \& Newberne PM (1994) Acute hepatotoxicity of aflatoxins. In Toxicology of Aflatoxins: Human Health, Veterinary and Agricultural Significance, pp. 3-26 [DL Eaton and JD Groopman, editors]. San Diego: Academic Press.

128. Plum LM, Rink L \& Haase H (2010) The essential toxin: impact of zinc on human health. Int J Environ Res Public Health 7, 342-365.

129. Imdad A \& Bhutta ZA (2011) Effect of preventive zinc supplementation on linear growth in children under 5 years of age in developing countries: a meta-analysis of studies for 
input to the lives saved tool. BMC Public Health 11, Suppl. 3, S22.

130. Harvey RB, Kubena LF, Huff WE, et al. (1989) Effects of aflatoxin, deoxynivalenol, and their combinations in the diets of growing pigs. Am J Vet Res 50, 602-607.

131. Mocchegiani E, Corradi A, Santarelli L, et al. (1998) Zinc, thymic endocrine activity and mitogen responsiveness (PHA) in piglets exposed to maternal aflatoxicosis $\mathrm{B}_{1}$ and $\mathrm{G}_{1}$. Vet Immunol Immunopathol 62, 245-260.

132. Olson LE, Ohlsson C \& Mohan S (2011) The role of GH/ IGF-I-mediated mechanisms in sex differences in cortical bone size in mice. Calcif Tissue Int $\mathbf{8 8}, 1-8$.

133. Yarru LP, Settivari RS, Antoniou E, et al. (2009) Toxicological and gene expression analysis of the impact of aflatoxin $\mathrm{B}_{1}$ on hepatic function of male broiler chicks. Poult Sci $\mathbf{8 8}$, $360-371$.

134. Huff WE, Kubena LF, Harvey RB, et al. (1988) Mycotoxin interactions in poultry and swine. J Anim Sci 66, 2351-2355.

135. Zamboni G, Dufillot D, Antoniazzi F, et al. (1996) Growth hormone-binding proteins and insulin-like growth factorbinding proteins in protein-energy malnutrition, before and after nutritional rehabilitation. Pediatr Res 39, 410-414

136. Ubagai T, Kikuchi T, Fukusato T, et al. (2010) Aflatoxin $B_{1}$ modulates the insulin-like growth factor-2 dependent signaling axis. Toxicol In Vitro 24, 783-789.

137. Bouhet S \& Oswald IP (2007) The intestine as a possible target for fumonisin toxicity. Mol Nutr Food Res 51, 925-931.

138. Caloni F, Spotti M, Pompa G, et al. (2002) Evaluation of fumonisin $B_{1}$ and its metabolites absorption and toxicity on intestinal cells line Caco-2. Toxicon 40, 1181-1188.

139. Kimanya ME, De Meulenaer B, Roberfroid D, et al. (2010) Fumonisin exposure through maize in complementary foods is inversely associated with linear growth of infants in Tanzania. Mol Nutr Food Res 54, 1659-1667.

140. Fandohan P, Zoumenou D, Hounhouigan DJ, et al. (2005) Fate of aflatoxins and fumonisins during the processing of maize into food products in Benin. Int J Food Microbiol 98, 249-259.

141. Pestka JJ (2010) Deoxynivalenol: mechanisms of action, human exposure, and toxicological relevance. Arch Toxicol 84, 663-679.

142. Arnold DL, McGuire PF, Nera EA, et al. (1986) The toxicity of orally administered deoxynivalenol (vomitoxin) in rats and mice. Food Chem Toxicol 24, 935-941.

143. Forsell JH, Witt MF, Tai JH, et al. (1986) Effects of 8-week exposure of the B6C3F1 mouse to dietary deoxynivalenol (vomitoxin) and zearalenone. Food Chem Toxicol 24, 213-219.

144. Young LG, McGirr L, Valli VE, et al. (1983) Vomitoxin in corn fed to young pigs. J Anim Sci 57, 655-664.

145. Prelusky DB (1997) Effect of intraperitoneal infusion of deoxynivalenol on feed consumption and weight gain in the pig. Nat Toxins 5, 121-125.

146. Prelusky DB (1993) The effect of low level deoxynivalenol on neurotransmitter levels measured in pig cerebral spinal fluid. J Environ Sci Health B 28, 731-761.

147. Prelusky DB (1994) The effect of deoxynivalenol on serotoninergic neurotransmitter levels in pig blood. J Environ Sci Health B 29, 1203-1218.

148. Pestka JJ, Islam Z \& Amuzie CJ (2008) Immunochemical assessment of deoxynivalenol tissue distribution following oral exposure in the mouse. Toxicol Lett 178, 83-87.

149. Fitzpatrick DW, Boyd KE, Wilson LM, et al. (1988) Effect of the trichothecene deoxynivalenol on brain biogenic monoamines concentrations in rats and chickens. J Environ Sci Health B 23, 159-170.
150. Girish CK, MacDonald EJ, Scheinin M, et al. (2008) Effects of feedborne Fusarium mycotoxins on brain regional neurochemistry of turkeys. Poult Sci 87, 1295-1302.

151. Prelusky DB, Yeung JM, Thompson BK, et al. (1992) Effect of deoxynivalenol on neurotransmitters in discrete regions of swine brain. Arch Environ Contam Toxicol 22, $36-40$.

152. Girardet C, Bonnet MS, Jdir R, et al. (2011) Central inflammation and sickness-like behavior induced by the food contaminant deoxynivalenol: a $\mathrm{PGE}_{2}$-independent mechanism. Toxicol Sci 124, 179-191.

153. Flannery BM, Wu W \& Pestka JJ (2011) Characterization of deoxynivalenol-induced anorexia using mouse bioassay. Food Chem Toxicol 49, 1863-1869.

154. Zhou HR, Yan D \& Pestka JJ (1998) Induction of cytokine gene expression in mice after repeated and subchronic oral exposure to vomitoxin (deoxynivalenol): differential toxin-induced hyporesponsiveness and recovery. Toxicol Appl Pharmacol 151, 347-358.

155. Ristimaki A (2004) Cyclooxygenase 2: from inflammation to carcinogenesis. Novartis Found Symp 256, 215-221.

156. Johnson PM, Vogt SK, Burney MW, et al. (2002) COX-2 inhibition attenuates anorexia during systemic inflammation without impairing cytokine production. Am J Physiol Endocrinol Metab 282, E650-E656.

157. Swiergiel AH \& Dunn AJ (2002) Distinct roles for cyclooxygenases 1 and 2 in interleukin-1-induced behavioral changes. J Pharmacol Exp Ther 302, 1031-1036.

158. Islam Z, Moon YS, Zhou HR, et al. (2002) Endotoxin potentiation of trichothecene-induced lymphocyte apoptosis is mediated by up-regulation of glucocorticoids. Toxicol Appl Pharmacol 180, 43-55.

159. Moon Y \& Pestka JJ (2002) Vomitoxin-induced cyclooxygenase-2 gene expression in macrophages mediated by activation of ERK and p38 but not JNK mitogen-activated protein kinases. Toxicol Sci 69, 373-382.

160. Iverson F, Armstrong C, Nera E, et al. (1995) Chronic feeding study of deoxynivalenol in $\mathrm{B} 6 \mathrm{C} 3 \mathrm{~F} 1$ male and female mice. Teratog Carcinog Mutagen 15, 283-306.

161. Amuzie CJ \& Pestka JJ (2010) Suppression of insulin-like growth factor acid-labile subunit expression - a novel mechanism for deoxynivalenol-induced growth retardation. Toxicol Sci 113, 412-421.

162. Boisclair YR, Wang J, Shi J, et al. (2000) Role of the suppressor of cytokine signaling-3 in mediating the inhibitory effects of interleukin-1 $\beta$ on the growth hormone-dependent transcription of the acid-labile subunit gene in liver cells. J Biol Chem 275, 3841-3847.

163. Heath KE, Argente J, Barrios V, et al. (2008) Primary acidlabile subunit deficiency due to recessive IGFALS mutations results in postnatal growth deficit associated with low circulating insulin growth factor (IGF)-I, IGF binding protein-3 levels, and hyperinsulinemia. J Clin Endocrinol Metab 93, $1616-1624$.

164. Marasas WF, Riley RT, Hendricks KA, et al. (2004) Fumonisins disrupt sphingolipid metabolism, folate transport, and neural tube development in embryo culture and in vivo: a potential risk factor for human neural tube defects among populations consuming fumonisin-contaminated maize. J Nutr 134, 711-716.

165. Greene ND \& Copp AJ (2005) Mouse models of neural tube defects: investigating preventive mechanisms. Am J Med Genet C Semin Med Genet 135C, 31-41.

166. Gelineau-van Waes J, Starr L \& Maddox J (2005) Maternal fumonisin exposure and risk for neural tube defects: mechanisms in an in vivo mouse model. Birth Defects Res A Clin Mol Teratol 73, 487-497. 
167. Missmer SA, Suarez L, Felkner M, et al. (2006) Exposure to fumonisins and the occurrence of neural tube defects along the Texas-Mexico border. Environ Health Perspect 114 , $237-241$.

168. Gelineau-van Waes J, Voss KA \& Stevens VL (2009) Maternal fumonisin exposure as a risk factor for neural tube defects. Adv Food Nutr Res 56, 145-181.

169. Luo Y, Yoshizawa T \& Katayama T (1990) Comparative study on the natural occurrence of Fusarium mycotoxins (trichothecenes and zearalenone) in corn and wheat from high-risk and low-risk areas for human esophageal cancer in China. Appl Environ Microbiol 56, 3723-3726.

170. Chu PS \& Li GY (1994) Simultaneous occurrence of fumonisin $B_{1}$ and other mycotoxins in moldy maize collected from the People's Republic of China in regions with high incidence of oesophageal cancer. Appl Environ Microbiol 60, 847-852.

171. Rheeder JP, Marasas WFO, Thiel PG, et al. (1992) Fusarium moniliforme and fumonisins in corn in relation to human eosophageal cancer in Transkei. Phytopathology 82, 353-357.

172. Hsia CC, Wu ZY, Li YS, et al. (2004) Nivalenol, a main Fusarium toxin in dietary foods from high-risk areas of cancer of esophagus and gastric cardia in China, induced benign and malignant tumors in mice. Oncol Rep 12, 449-456.

173. Hsia CC, Wu JL, Lu XQ, et al. (1988) Natural occurrence and clastogenic effects of nivalenol, deoxynivalenol, 3-acetyldeoxynivalenol, 15-acetyl-deoxynivalenol, and zearalenone in corn from a high-risk area of esophageal cancer. Cancer Detect Prev 13, 79-86.

174. Hsia CC, Tzian BL \& Harris CC (1983) Proliferative and cytotoxic effects of Fusarium $\mathrm{T}_{2}$ toxin on cultured human fetal esophagus. Carcinogenesis 4, 1101-1107.

175. Howard PC, Eppley RM, Stack ME, et al. (2001) Fumonisin $\mathrm{B}_{1}$ carcinogenicity in a two-year feeding study using F344 rats and B6C3F1 mice. Environ Health Perspect 109, Suppl. 2, 277-282.

176. Phillips TD, Afriyie-Gyawu E, Williams J, et al. (2008) Reducing human exposure to aflatoxin through the use of clay: a review. Food Addit Contam Part A Chem Anal Control Expo Risk Assess 25, 134-145.

177. El-Nezami HS, Polychronaki NN, Ma J, et al. (2006) Probiotic supplementation reduces a biomarker for increased risk of liver cancer in young men from Southern China. Am J Clin Nutr 83, 1199-1203.

178. Piekkola S, Turner PC, Abdel-Hamid M, et al. (2012) Characterisation of aflatoxin and deoxynivalenol exposure among pregnant Egyptian women. Food Add Contam Part A Chem Anal Expo Risk Assess 29, 962-971.

179. Gratz S, Täubel M, Juvonen RO, et al. (2006) Lactobacillus rhamnosus strain GG modulates intestinal absorption of aflatoxin $\mathrm{B}_{1}$ and its fecal excretion and toxicity in rat. Appl Environ Microbiol 72, 7398-7400.

180. James B, Adda C, Cardwell K, et al. (2007) Public information campaign on aflatoxin contamination of maize grains in market stores in Benin, Ghana and Togo. Food Addit Contam 24, 1283-1291. 